\title{
Overexpression of the transcription factor RAP2.6 leads to enhanced callose deposition in syncytia and enhanced resistance against the beet cyst nematode Heterodera schachtii in Arabidopsis roots
}

\author{
Muhammad Amjad Ali ${ }^{1,2}$, Amjad Abbas ${ }^{1}$, David P Kreil ${ }^{3,4}$ and Holger Bohlmann ${ }^{1 *}$
}

\begin{abstract}
Background: Cyst nematodes invade the roots of their host plants as second stage juveniles and induce a syncytium which is their source of nutrients throughout their life. A transcriptome analysis of syncytia induced by the beet cyst nematode Heterodera schachtii in Arabidopsis roots has shown that gene expression in the syncytium is different from that of the root with thousands of genes upregulated or downregulated. Among the downregulated genes are many which code for defense-related proteins. One gene which is strongly downregulated codes for the ethylene response transcription factor RAP2.6. The genome of Arabidopsis contains 122 ERF transcription factor genes which are involved in a variety of developmental and stress responses.

Results: Expression of RAP2.6 was studied with RT-PCR and a promoter::GUS line. During normal growth conditions the gene was expressed especially in roots and stems. It was inducible by Pseudomonas syringae but downregulated in syncytia from a very early time point on. Overexpression of the gene enhanced the resistance against $H$. schachtii which was seen by a lower number of nematodes developing on these plants as well as smaller syncytia and smaller female nematodes. A T-DNA mutant had a reduced RAP2.6 transcript level but this did not further increase the susceptibility against $H$. schachtii. Neither overexpression lines nor mutants had an effect on $P$. syringae. Overexpression of RAP2.6 led to an elevated expression of JA-responsive genes during early time points after infection by H. schachtii. Syncytia developing on overexpression lines showed enhanced deposition of callose.

Conclusions: Our results showed that $H$. schachtii infection is accompanied by a downregulation of RAP2.6. It seems likely that the nematodes use effectors to actively downregulate the expression of this and other defenserelated genes to avoid resistance responses of the host plant. Enhanced resistance of RAP2.6 overexpression lines seemed to be due to enhanced callose deposition at syncytia which might interfere with nutrient import into syncytia.
\end{abstract}

\footnotetext{
* Correspondence: holger.bohlmann@boku.ac.at

'Division of Plant Protection, Department of Crop Sciences, University of Natural Resources and Life Sciences Vienna, UFT Tulln, Konrad Lorenz Str. 24, 3430, Tulln, Austria

Full list of author information is available at the end of the article
} 


\section{Background}

Nematodes are multicellular unsegmented soft-bodied worms and belong to the phylum Nematoda. They are ubiquitous in nature and can be found everywhere ranging from the sediments of the oceans to high mountains and in a variety of climates [1]. Plant parasitic nematodes are obligate biotrophic parasites generally attacking the roots of many plant species. They have a wide host range and can have adverse effects on the yield of crop plants by damaging the crops either directly or as virus vectors. The worldwide annual crop losses caused by plant parasitic nematodes have been estimated at 157 billion dollars [2]

Several economically important species are pathogens of different crop plants and the cyst and root-knot nematodes within the family Heteroderidae are among the most important. They are obligate endoparasites of plant roots which they enter as second stage juveniles (J2 larvae) and establish specialized feeding structures [3,4]. Root-knot nematodes belonging to the genus Meloidogyne induce a feeding structure comprised of several giant cells [5]. Cyst nematodes of the genera Heterodera and Globodera hatch from eggs as J2 larvae and pierce the host plant roots by continuously striking their stylet just around the root elongation zone. After entering the root, they migrate intracellularly through the root cortex to find the vascular cylinder. When the nematodes reach the vascular bundle, they initiate a specialized feeding site called a syncytium [6]. The syncytium originates from a single root cell (ISC, initial syncytial cell) which expands by incorporating up to several hundred adjacent cells by local cell wall dissolution. It has been shown that plant encoded cell wall modifying and degrading enzymes such as expansins, pectinases, and cellulases are involved in this process [7-11]. The syncytium becomes the only food source for the nematodes as they develop through subsequent sedentary life stages $[12,13]$. Adult male cyst nematodes become mobile again and leave their feeding site to mate with females while females remain attached with their syncytium. After mating, the female cyst nematode carries on feeding but dies after the completion of egg development, leaving several hundred eggs contained within its enlarged body. The outer layer of the female subsequently hardens to form a cyst, which protects the eggs until infective J2 hatch under favorable conditions [3].

The establishment of the syncytium from the ISC inside the vascular cylinder is most likely commenced through secretions of the nematode and a coordinated expression of plant genes [9-11,14,15]. Recently, we have performed a transcriptome analysis of 5 and 15 dpi (days post infection) syncytia induced by $H$. schachtii in Arabidopsis roots which revealed that $34.2 \%$ out of a total of 21,138 Arabidopsis genes were differentially expressed as compared to uninfected control root sections [16]. Of these differentially expressed genes, $18.4 \%$
(3893) were upregulated while $15.8 \%$ (3338) were downregulated. Upregulated genes included for instance those coding for expansins, cellulases, and pectate lyases [9-11] which are involved in cell wall degradation and genes coding for myo-inositol oxygenases [17]. On the other hand, genes which were strongly repressed after nematode infection were related to defense responses of the plant [16]. One strongly downregulated group comprised for instance genes coding for peroxidases and out of 100 differentially expressed genes with the strongest decrease in expression, 14 were peroxidases [16].

Another gene which was significantly downregulated in syncytia as compared to control root sections was the RAP2.6 gene [16]. Members of this family of proteins contain the APETALA2 (AP2) domain and were first defined as a family encoded by 12 genes in Arabidopsis. APETALA2 was found to be involved in the control of Arabidopsis flower and seed development and encodes a putative transcription factor that is distinguished by a novel DNA binding motif referred to as the AP2 domain [18]. Related proteins were originally identified as transcriptional regulators that function downstream of ethylene signaling [19]. All these and other proteins are now included in the AP2/ERF superfamily which has 147 members in Arabidopsis [20]. The largest group of these includes the ethylene response factors (ERFs) with 122 members. This group contains the originally described RAP2 proteins in different subgroups.

The RAP2.6 gene has been reported to respond to various biotic and abiotic stresses indicating its role in the regulation of these stresses. RAP2.6 was found to be involved in the Arabidopsis response to abscisic acid (ABA), wounding, jasmonic acid (JA), salt, cold, and osmotic stresses [21-24]. The activation of RAP2.6 in response to type III secretions of virulent and avirulent strains of Pseudomonas syringae was reported to be dependent on Coil (coronatine-insenstive 1) by [25]. Similarly, RAP2.6 was identified as a Coi1- dependent JA-inducible transcription factor [26]. Using a RAP2.6:: $L U C$ reporter gene, it was found that RAP2.6 was induced by the virulent bacterium $P$. syringae pv tomato but not by the non-adapted bacterium $P$. syringae $\mathrm{pv}$ phaseolicola [27]. It is well known that $P$. syringae uses coronatin to induce the JA pathway in the host plant to suppress salicylic acid (SA) dependent resistance [28]. RAP2.6 was also highly upreguled after $24 \mathrm{~h}$ in response to the diamond black moth [29]. All these reports indicate that the RAP2.6 gene is involved in the JA response. Indeed, this gene was among $14 \mathrm{AP} 2 / \mathrm{ERF}$ genes that were found in a screening for JA-inducible ERF transcription factors [30] which also included ORA59 [31]. Since RAP2.6 was one of the most strongly downregulated genes in syncytia [16] we have studied this gene in more detail. We reasoned that this gene 
might be downregulated by $H$. schachtii to avoid a plant resistance response. We have therefore tested if overexpression of the RAP2.6 gene might lead to higher resistance against $H$. schachtii.

\section{Results}

Expression of the ERF gene family in syncytia

We recently performed a transcriptome analysis of syncytia induced by $H$. schachtii in Arabidopsis roots [16]. The data from this analysis were used to specifically analyse the expression of the ERF genes in syncytia. The ERF family contains 122 members of which 105 are included on the Arabidopsis GeneChip. Our analysis (Table 1 and Additional file 1) indicated that only 7 of these genes showed a significant upregulation in syncytia as compared to control root sections while 32 showed a significant downregulation (false discovery rate $<5 \%$ ). Comparing 15 dpi syncytia with 5 dpi syncytia showed that 7 genes were significantly higher expressed in 15 dpi syncytia compared to 5 dpi syncytia (Additional file 2). The genes that showed the strongest downregulation in syncytia were At5g25810 (TNY), At1g78080 (RAP2.4), At2g20880, At3g50260 (CEJ1 or DEAR1 [32]) and At1g43160 (RAP2.6), which was the most suppressed gene in this family. Because several reports found that it is involved in plant resistance and the GeneChip data showed the strongest downregulation for RAP2.6 (expression level 0.91 in syncytia and 9.97 in control root sections), we studied the expression of this gene in detail by using GUS analysis and qRT-PCR in syncytia.

Promoter::GUS and qRT-PCR analysis of RAP2.6 expression in syncytia

The expression of RAP2.6 in syncytia was studied by using qRT-PCR for which syncytia were excised at 5,10 and $15 \mathrm{dpi}$. For comparison with the GeneChip results, the same control root segments were used as in that study [16]. RAP2.6 was highly downregulated in syncytia compared with controls at all time points (Figure 1), thus validating the GeneChip data which also showed strong suppression of this gene in syncytia.

To further study the expression of RAP2.6 in syncytia, a promRAP2.6::GUS fusion was constructed in pMAARed [33] and used to transform Arabidopsis plants. A representative homozygous promoter::GUS line was infected with second stage juveniles under sterile conditions and stained for the detection of GUS activity at different time-points after infection, i.e. 1, 3, 5, 10, 12 and 15 dpi along with uninfected roots (Figure 2). GUS expression was seen in the vicinity of the nematode infection site at $1 \mathrm{dpi}$ but had disappeared in the ISC. At 3 and $5 \mathrm{dpi}$, expression was switched off in most of the feeding sites but GUS staining was still visible in the cells surrounding the syncytia. At 10,12 , and $15 \mathrm{dpi}$,
Table 1 Expression of ERF genes in syncytia and control root segments according to GeneChip data

\begin{tabular}{|c|c|c|c|c|c|}
\hline$\overline{I D}$ & Gene & Syn & Root & Syn vs root & $q$ \\
\hline At1g43160 & RAP2.6 & 0.91 & 9.97 & -9.06 & $9.8 \mathrm{E}-8$ \\
\hline At3g50260 & CEJ1/ DEAR1 & 3.78 & 9.89 & -6.11 & 7.1E-5 \\
\hline At2g20880 & AtERF53 & 2.13 & 7.73 & -5.61 & $9.8 \mathrm{E}-8$ \\
\hline At1g78080 & WIND1/RAP2.4 & 3.35 & 8.43 & -5.08 & $1.0 \mathrm{E}-5$ \\
\hline At5g25810 & TINY & 2.08 & 6.33 & -4.24 & $8.2 E-7$ \\
\hline At5g05410 & DREB2A & 5.67 & 9.12 & -3.45 & $0.10 \%$ \\
\hline At1g22190 & WIND2 & 4.31 & 7.54 & -3.23 & $7.3 \mathrm{E}-5$ \\
\hline At1g53910 & RAP2.12 & 4.33 & 6.50 & -2.17 & $3.0 \%$ \\
\hline At5g44210 & AtERF9 & 3.20 & 5.34 & -2.14 & $0.44 \%$ \\
\hline At1g06160 & ORA59 & 3.25 & 5.37 & -2.12 & $0.04 \%$ \\
\hline At4g17490 & AtERF6 & 4.12 & 6.21 & -2.08 & $1.7 \%$ \\
\hline At4g39780 & & 3.71 & 5.68 & -1.97 & $0.07 \%$ \\
\hline At5g19790 & RAP2.11 & 3.59 & 5.55 & -1.96 & $0.01 \%$ \\
\hline At2g23340 & & 9.41 & 11.26 & -1.85 & $2.8 \%$ \\
\hline At5g61590 & & 5.81 & 7.63 & -1.82 & $1.7 \%$ \\
\hline At5g61600 & & 5.67 & 7.41 & -1.74 & $1.5 \%$ \\
\hline At5g47230 & AtERF5 & 3.66 & 5.16 & -1.50 & $0.53 \%$ \\
\hline At3g20310 & AtERF7 & 5.64 & 7.05 & -1.41 & $2.9 \%$ \\
\hline At1g64380 & & 2.25 & 3.58 & -1.34 & $1.4 \%$ \\
\hline At4g36900 & RAP2.10 & 6.29 & 7.41 & -1.12 & $3.0 \%$ \\
\hline At5g67190 & & 4.82 & 5.93 & -1.11 & $41.7 \%$ \\
\hline At2g44940 & & 4.61 & 5.70 & -1.09 & $0.61 \%$ \\
\hline At4g16750 & & 2.80 & 3.83 & -1.03 & $0.04 \%$ \\
\hline At1g72360 & & 8.47 & 9.50 & -1.02 & $14.2 \%$ \\
\hline At5g07580 & & 5.65 & 6.63 & -0.98 & $0.10 \%$ \\
\hline At4g17500 & AtERF1 & 5.75 & 6.73 & -0.98 & $0.89 \%$ \\
\hline At3g14230 & RAP2.2 & 4.88 & 5.76 & -0.88 & $23.4 \%$ \\
\hline At2g25820 & & 2.70 & 3.54 & -0.84 & $2.7 \%$ \\
\hline At4g25480 & & 3.04 & 3.87 & -0.83 & $2.3 \%$ \\
\hline At3g61630 & & 2.18 & 2.95 & -0.77 & $0.61 \%$ \\
\hline At5g18560 & & 3.10 & 3.86 & -0.76 & $0.81 \%$ \\
\hline At1g22985 & & 6.17 & 6.91 & -0.74 & $9.6 \%$ \\
\hline At5g18450 & & 4.03 & 4.76 & -0.73 & $7.7 \%$ \\
\hline At3g15210 & AtERF4/RAP2.5 & 5.14 & 5.81 & -0.67 & $2.3 \%$ \\
\hline At5g51990 & $C B F 4 / D R E B 1 D$ & 3.20 & 3.74 & -0.55 & $2.9 \%$ \\
\hline At1g53170 & AtERF8 & 4.33 & 4.75 & -0.42 & $13.9 \%$ \\
\hline At5g67000 & & 4.04 & 4.45 & -0.41 & $44.2 \%$ \\
\hline At5g13910 & LEP & 2.96 & 3.35 & -0.39 & $4.1 \%$ \\
\hline At1g46768 & RAP2.1 & 3.70 & 4.08 & -0.38 & $2.7 \%$ \\
\hline At2g46310 & & 3.41 & 3.74 & -0.34 & $13.5 \%$ \\
\hline At2g40220 & $A B / 4$ & 3.27 & 3.58 & -0.31 & $7.7 \%$ \\
\hline At3g23230 & TDR1 & 2.93 & 3.24 & -0.31 & $30.1 \%$ \\
\hline
\end{tabular}


Table 1 Expression of ERF genes in syncytia and control root segments according to GeneChip data (Continued)

\begin{tabular}{|c|c|c|c|c|c|}
\hline At4g25490 & CBF1/DREB1B & 3.30 & 3.61 & -0.31 & $8.7 \%$ \\
\hline At2g31230 & AtERF15 & 3.59 & 3.87 & -0.29 & $14.6 \%$ \\
\hline At4g28140 & & 2.75 & 3.02 & -0.27 & $16.6 \%$ \\
\hline At3g60490 & & 3.71 & 3.97 & -0.25 & $30.1 \%$ \\
\hline At4g11140 & & 2.67 & 2.91 & -0.24 & $20.2 \%$ \\
\hline At5g25390 & SHN3 & 3.97 & 4.20 & -0.23 & $44.2 \%$ \\
\hline At1g15360 & WIN1/SHN1 & 3.06 & 3.26 & -0.20 & $30.7 \%$ \\
\hline At5g65130 & WIND4 & 2.44 & 2.64 & -0.20 & $14.2 \%$ \\
\hline At4g18450 & & 3.34 & 3.53 & -0.19 & $19.5 \%$ \\
\hline At5g11590 & & 2.46 & 2.65 & -0.19 & $27.2 \%$ \\
\hline At1g75490 & & 2.64 & 2.82 & -0.19 & $38.5 \%$ \\
\hline At1g44830 & & 3.14 & 3.30 & -0.16 & $41.7 \%$ \\
\hline At1g33760 & & 2.14 & 2.29 & -0.14 & $30.7 \%$ \\
\hline At4g31060 & & 3.87 & 3.99 & -0.13 & $80.3 \%$ \\
\hline At5g67010 & & 2.62 & 2.74 & -0.12 & $45.1 \%$ \\
\hline At1g63030 & DDF1 & 1.97 & 2.07 & -0.10 & $48.3 \%$ \\
\hline At1g22810 & & 2.26 & 2.35 & -0.09 & $52.8 \%$ \\
\hline At3g23220 & & 3.52 & 3.61 & -0.09 & $52.8 \%$ \\
\hline At5g43410 & & 3.93 & 4.01 & -0.08 & $67.5 \%$ \\
\hline At1g28160 & & 2.49 & 2.55 & -0.06 & $70.3 \%$ \\
\hline At1g28370 & AtERF11 & 5.00 & 5.05 & -0.05 & $92.5 \%$ \\
\hline At2g22200 & & 2.70 & 2.75 & -0.05 & $80.3 \%$ \\
\hline At5g25190 & & 3.06 & 3.11 & -0.05 & $80.3 \%$ \\
\hline At5g07310 & & 3.11 & 3.15 & -0.04 & $86.9 \%$ \\
\hline At1g80580 & & 3.17 & 3.21 & -0.04 & $91.2 \%$ \\
\hline At1g77640 & & 4.41 & 4.44 & -0.03 & $91.2 \%$ \\
\hline At1g12630 & & 4.85 & 4.88 & -0.03 & $91.2 \%$ \\
\hline At3g16280 & & 3.97 & 3.99 & -0.02 & $91.2 \%$ \\
\hline At2g36450 & & 3.01 & 3.03 & -0.02 & $91.2 \%$ \\
\hline At2g35700 & & 2.78 & 2.80 & -0.02 & $91.6 \%$ \\
\hline At1g01250 & & 3.24 & 3.24 & 0.00 & $99.3 \%$ \\
\hline At4g25470 & CBF2/DREB1C & 4.30 & 4.30 & 0.01 & $96.8 \%$ \\
\hline At1g50640 & AtERF3 & 2.95 & 2.94 & 0.01 & $95.6 \%$ \\
\hline At3g57600 & & 2.73 & 2.70 & 0.03 & $91.2 \%$ \\
\hline At1g12610 & & 2.58 & 2.55 & 0.03 & $91.2 \%$ \\
\hline At2g33710 & & 2.82 & 2.78 & 0.04 & $78.0 \%$ \\
\hline At3g23240 & ERF1 & 3.49 & 3.45 & 0.05 & $81.8 \%$ \\
\hline At2g20350 & & 2.61 & 2.56 & 0.05 & $86.9 \%$ \\
\hline At1g19210 & & 3.22 & 3.14 & 0.08 & $73.9 \%$ \\
\hline At5g53290 & & 3.45 & 3.36 & 0.10 & $67.4 \%$ \\
\hline At2g44840 & AtERF13 & 3.75 & 3.65 & 0.10 & $67.0 \%$ \\
\hline At1g68550 & & 5.06 & 4.93 & 0.13 & $53.9 \%$ \\
\hline At1g36060 & WIND3 & 4.21 & 4.07 & 0.15 & $50.5 \%$ \\
\hline
\end{tabular}

Table 1 Expression of ERF genes in syncytia and control root segments according to GeneChip data (Continued)

\begin{tabular}{llcllc}
\hline At5g52020 & & 3.87 & 3.69 & 0.18 & $56.1 \%$ \\
At1g28360 & AtERF12 & 2.84 & 2.63 & 0.21 & $16.6 \%$ \\
At4g32800 & & 3.70 & 3.48 & 0.22 & $14.2 \%$ \\
At3g11020 & DREB2B & 4.75 & 4.51 & 0.24 & $25.4 \%$ \\
At5g47220 & AtERF2 & 4.12 & 3.87 & 0.26 & $18.9 \%$ \\
At1g25470 & & 5.06 & 4.79 & 0.26 & $36.0 \%$ \\
At2g38340 & DREB2E & 2.86 & 2.58 & 0.27 & $9.6 \%$ \\
At1g74930 & 3.78 & 3.35 & 0.43 & $5.7 \%$ \\
At4g23750 & 3.72 & 3.28 & 0.44 & $14.2 \%$ \\
At1g71130 & 6.75 & 6.27 & 0.48 & $14.2 \%$ \\
At3g25890 & 3.96 & 3.37 & 0.59 & $7.1 \%$ \\
At5g51190 & 5.43 & 4.82 & 0.61 & $11.4 \%$ \\
At5g61890 & & $\mathbf{4 . 8 6}$ & $\mathbf{4 . 2 5}$ & $\mathbf{0 . 6 2}$ & $\mathbf{0 . 8 9} \%$ \\
At1g71450 & $\mathbf{3 . 2 3}$ & $\mathbf{2 . 5 8}$ & $\mathbf{0 . 6 5}$ & $\mathbf{0 . 7 3} \%$ \\
At2g47520 & 4.36 & 3.62 & 0.74 & $8.3 \%$ \\
At1g77200 & $\mathbf{3 . 1 8}$ & $\mathbf{2 . 4 3}$ & $\mathbf{0 . 7 5}$ & $\mathbf{0 . 6 1 \%}$ \\
At5g13330 & $\mathbf{6 . 0 3}$ & $\mathbf{5 . 1 7}$ & $\mathbf{0 . 8 5}$ & $\mathbf{2 . 2} \%$ \\
At1g21910 & $\mathbf{4 . 5 6}$ & $\mathbf{3 . 5 8}$ & $\mathbf{0 . 9 8}$ & $\mathbf{1 . 4 \%}$ \\
At4g34410 & $\mathbf{4 . 4 0}$ & $\mathbf{2 . 8 4}$ & $\mathbf{1 . 5 6}$ & $\mathbf{0 . 7 7 \%}$ \\
At3g16770 & AtEBP/RAP2.3 & $\mathbf{1 1 . 1 5}$ & $\mathbf{9 . 3 4}$ & $\mathbf{1 . 8 1}$ & $\mathbf{1 . 7 \%}$
\end{tabular}

At4g13620

At4g06746

RAP2.9

At5g21960

At1g71520

At1g63040

At2g40350

DREB2H

At2g40340

At5g 11190

SHN2

At4g27950

At1g49120

At1g03800

AtERF10

At1g12890

At1g12980

ESR1/DRN

At1g24590

At1g04370

AtERF14

At5950080

At5g64750 ABR1

The data for microaspirated syncytia at $5 \mathrm{dpi}$ and $15 \mathrm{dpi}$ were compared with control roots (the elongation zone without root tip was used as control). The third and fourth columns show the normalized expression values on a $\log _{2}$ scale. The differences (fold changes) between the pairwise samples displayed (fifth column) are accordingly normalized $\log _{2}$ ratios (see the Online Methods section for details). The q-values in column 6 indicate significance after correction for multiple testing controlling the False Discovery Rate. Genes with a significant up- or downregulation (false discovery rate $<5 \%$ ) are shown in bold. A dash (-) indicates that the gene is not represented on the GeneChip. 


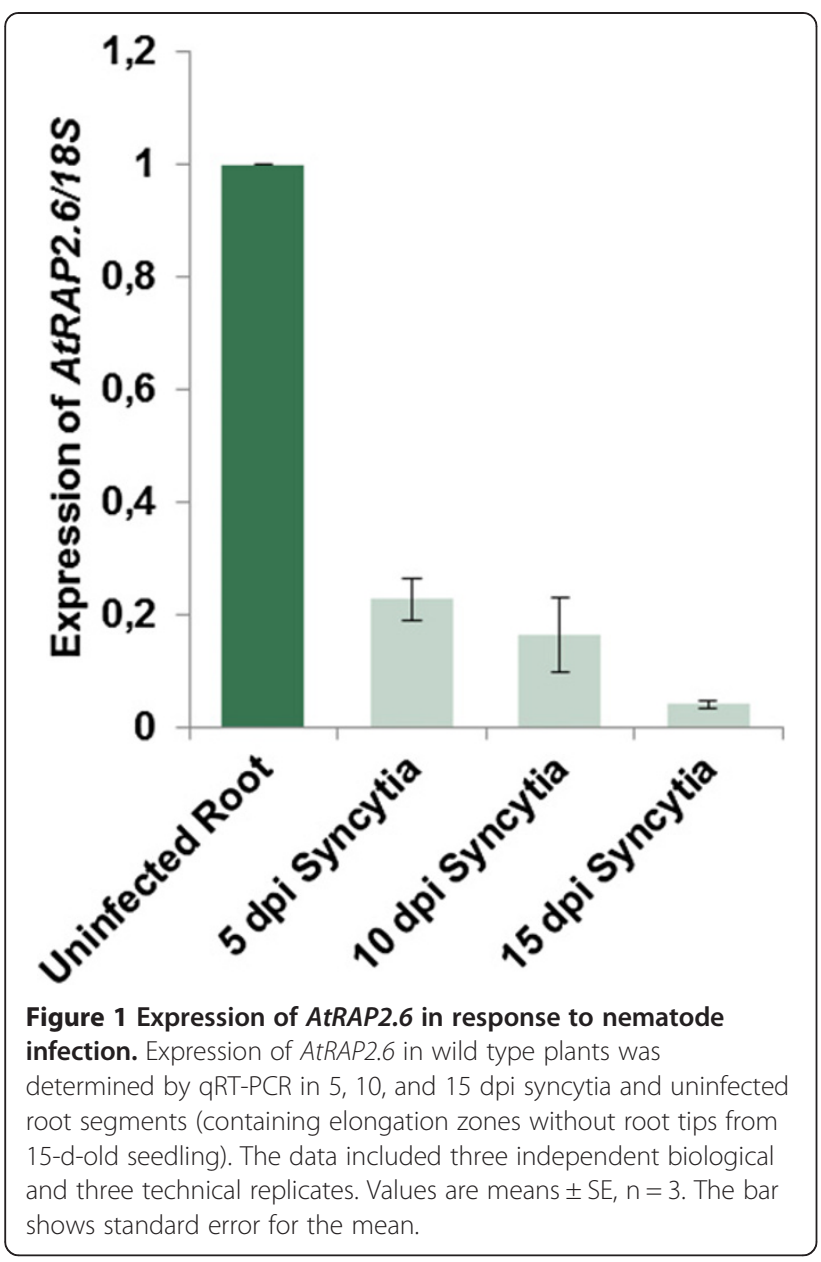

GUS expression was neither found in syncytia nor in cells surrounding the syncytia. On the other hand, highly intense expression was found in the uninfected roots of promoterRAP2.6::GUS plants in 20-d-old plants (corresponding to $5 \mathrm{dpi}$ ), which was then confined to younger root parts and lateral roots in 25- and 30-d-old roots (corresponding to 10 and $15 \mathrm{dpi}$ ). The promoterRAP2.6:: GUS analysis also confirmed the GeneChip data.

A promRAP2.6::GUS line has been reported before, however, the authors showed only pictures for seedlings, flowers, and a siliqua [24]. We have therefore included here a developmental analysis of our line (Figure 3). GUS staining in 1-d-old seedlings was observed in cotyledons and roots but not root tips. In 5-d-old seedlings promoter activity was found in roots but not root tips and in the hypocotyl. Cotyledons at this stage did not show GUS staining. A similar result was found for 14-d-old seedlings but older roots were not stained. No staining was found in older rosette leaves, except some small very weak patches in some leaves (compare also Figure 4). After flowering, a staining was found in the main leaf vein. Cauline leaves also showed staining in leaf veins and a weak patchy staining. We also detected GUS staining in stems, especially in the vasculature. In flowers the GUS expression was confined to the carpels and in young siliques staining was mainly found in the replum while older siliques only showed some GUS expression in parts of the valves. GUS expression was confirmed by RT-PCR (Figure 5) which detected the strongest RAP2.6 expression in roots and stems. GUS expression after infiltration of $P$. syringae pv tomato DC3000 (Figure 5) also confirmed the report of $[25,27]$ that $R A P 2.6$ is induced by $P$. syringae.

\section{Overexpression lines and mutants of RAP2.6}

Several reports have shown that RAP2.6 was involved in resistance responses $[25,27,29,30]$. This indicated that nematodes might downregulate the expression of RAP2.6 to avoid resistance responses of the plant. We therefore produced overexpression lines using the vector pMAA-Red. The selection of homozygous lines was made first by visual observation based on the degree of DsRed fluorescence in seeds of different lines as described [33]. Three lines which showed strong fluorescence were made homozygous followed by qRT-PCR and compared to wild type using $18 \mathrm{~S}$ as an internal control (Figure 6). The 14-d-old seedlings of selected overexpression lines showed a much higher transcript level as compared to wild type (Col). As has been reported before [24], RAP2.6 overexpression resulted in early flowering but the phenotype of seedlings was not different from wild type in our assays (data not shown).

For RAP2.6 one knock-out mutant (GK-053G11) with several T3 seed lines was available. The insertion of the TDNA is in the 5 'untranslated leader region (Figure 7A). The T-DNA insertions of two T3 lines were confirmed by PCR (Figure 7B) as described in Material and Methods. The transcript level of homozygous lines was measured by qRT-PCR which showed that RAP2.6 was approximately $50 \%$ downregulated in seedlings (Figure $7 \mathrm{C}$ ). The downregulation of RAP2.6 in these mutants resulted in late flowering of the mutant plants but otherwise the phenotype of seedlings was not different from wild type seedlings (data not shown).

\section{Overexpression of RAP2.6 has no effect against Pseudomonas syringae}

As $R A P 2.6$ was reported to be highly activated by virulent and avirulant strains of $P$. syringae $[25,27]$ which we confirmed by analysis of a promRAP2.6::GUS line (Figure 5), we also tested the effect of overexpression or mutants of RAP2.6 on the pathogenic strain P. syringae pv tomato DC3000. Neither overexpression nor knocking out of RAP2.6 had an effect on the growth of P. syringae pv tomato DC3000 as compared to wild type plants (Figure 8). This suggested that $R A P 2.6$ is not involved in resistance or susceptibility against $P$. syringae pv tomato DC3000. 


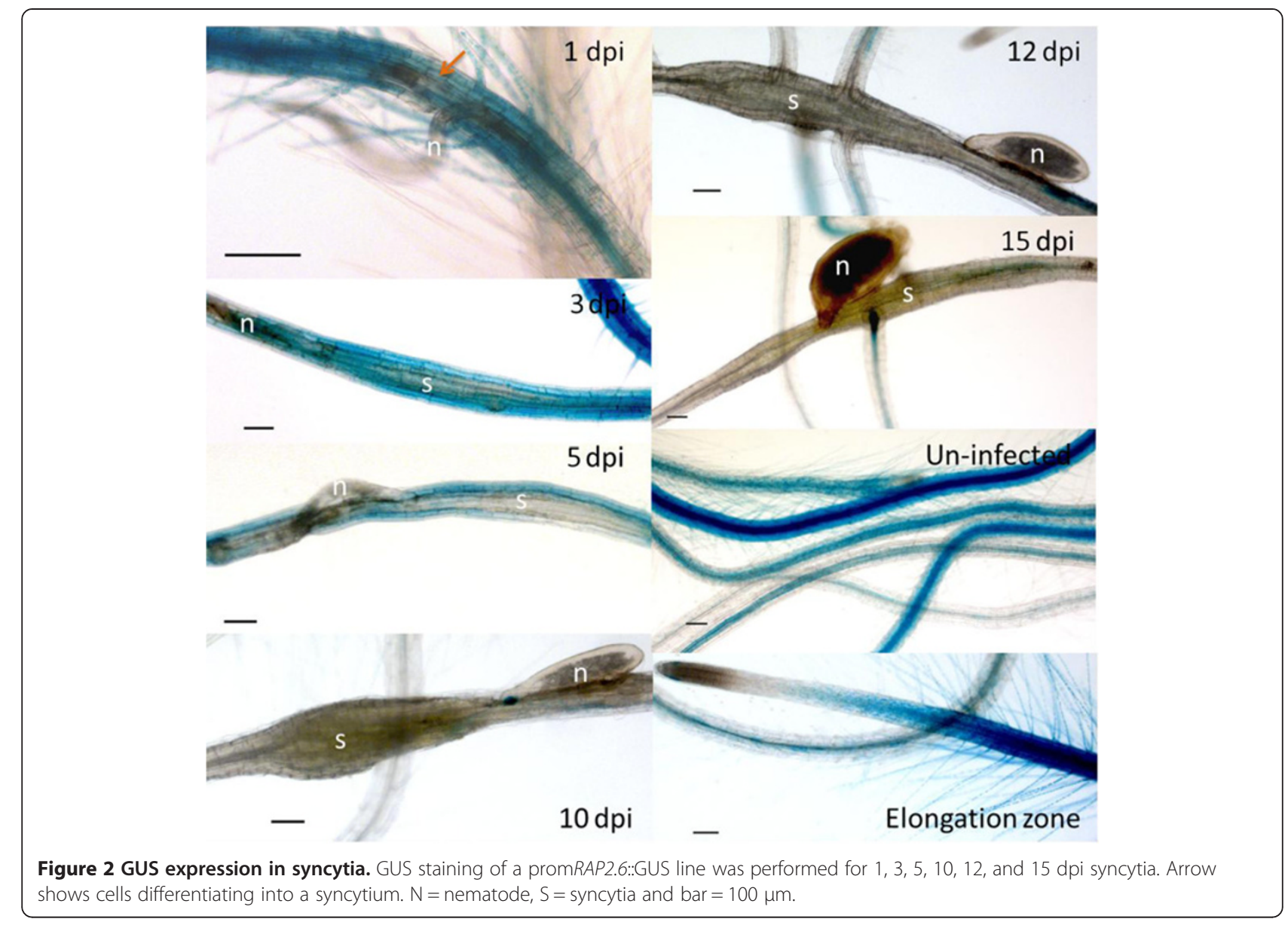

\section{Overexpression of RAP2.6 results in resistance against nematodes}

Since expression in seedlings might be different from expression in syncytia, we determined the expression level of RAP2.6 in syncytia of mutant lines and overexpression lines (Figure 9). Compared to wild type plants, expression in syncytia at 5 and $10 \mathrm{dpi}$ was much lower in both mutant lines but strongly upregulated in overexpression lines. In general, the expression was lower in 10 dpi syncytia.

We performed nematode infection assays with two overexpression lines and the two mutant lines and compared the results to wild type plants (Figure 10). Both overexpression lines supported a significantly lower number of female and male nematodes as compared to the wild type. The overexpression lines also resulted in impaired development of syncytia associated with female nematode and female nematodes which were smaller as compared to those from wild type plants. However, the T-DNA insertion mutants did not show significant differences from wild type in terms of number of female and male nematodes or size of female nematodes. Only the size of syncytia associated with female nematodes was affected by this mutation and was significantly larger for line rap2.6-2.
Nematode resistance in overexpression lines might be regulated by SA and JA pathways

The roots of overexpression and mutant lines along with wild type Col were infected with J2 larvae in 2 independent experiments. RNA was isolated from uninfected, 1 dpi and 2 dpi roots along with 5 dpi syncytia. The expression of marker genes which are induced by ethylene (ET) (PR4), SA (PR1 and PR5), JA/ET (Pdf2.1a), and JA (AOS and LOX2) was determined by RT-PCR in these samples (Figure 11). Uninfected wild type together with overexpression lines and mutants showed similar expression in uninfected roots with low levels of AOS and PR4 and no expression of PR1, PR5, Pdf2.1a, and LOX2 (Figure 11A). However, SA inducible genes PR1 and PR5 were slightly induced at $1 \mathrm{dpi}$ in overexpression lines as compared with wild type $(\mathrm{Col})$ and mutants which indicated that the initial responses of the plant might be regulated by SA (Figure 11B). Similarly, the JA-inducible gene $A O S$ showed upregulation at $1 \mathrm{dpi}$ in overexpression lines which was more prominent than PR1 and PR5. On the other hand, Pdf2.1a, LOX2 and PR4 showed no upregulation in either overexpression lines or mutants and as compared to wild type (Figure 11B). At $2 \mathrm{dpi}$, most of the genes showed the same expression as in $1 \mathrm{dpi}$ except 


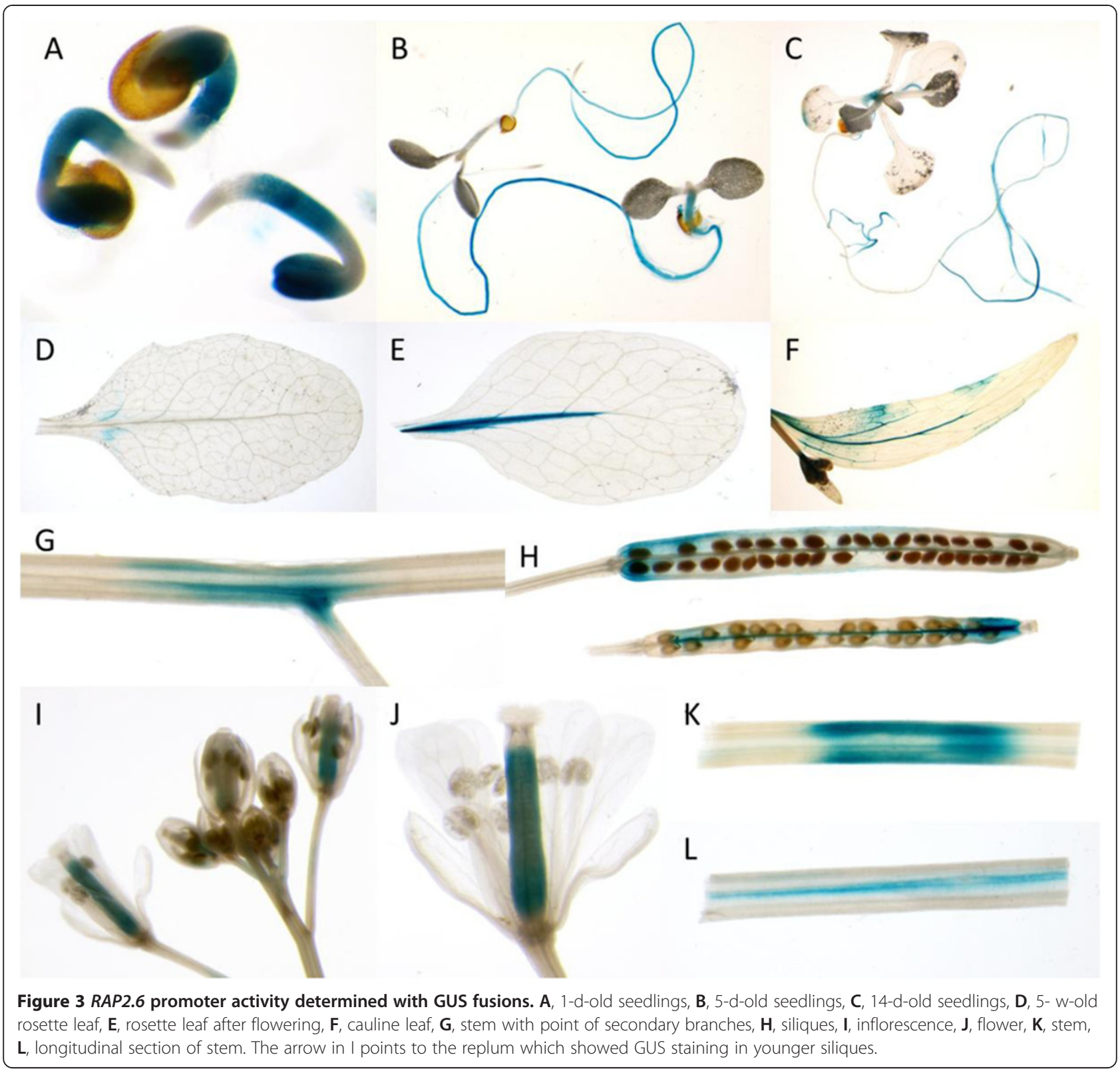

Pdf2.1a which was induced in overexpression lines (Figure 11C). In 5 dpi syncytia, expression of all tested genes was similar to the wild type in the overexpression lines and the mutant lines (Figure 11D). Compared to uninfected controls, nematode infection led to an early plant response which was indicated by upregulation of $P R 1$, PR5, Pdf1.2a, AOS, and PR4.

\section{Callose deposition is enhanced in RAP2.6 overexpression lines}

We performed callose staining of 5, 10 and 15 dpi syncytia which showed that the overexpression lines accumulated more callose as compared to the mutants and wild type plants at all the time points. Representative pictures are shown in Figure 12. Callose deposits were more prominent and higher in number in the feeding sites of overexpression lines. Quantification of the number of dots confirmed the visual observation (Figure 13). The number of callose deposits at the feeding sites was significantly higher in the overexpression lines at all time points as compared to wild type while the mutant lines had a significantly lower number of deposits.

\section{Discussion}

ERF genes are preferentially downregulated in syncytia Of the 105 ERF genes included on the Arabidopsis GeneChip, 32 were significantly downregulated in syncytia induced by $H$. schachtii in Arabidopsis roots while 
A

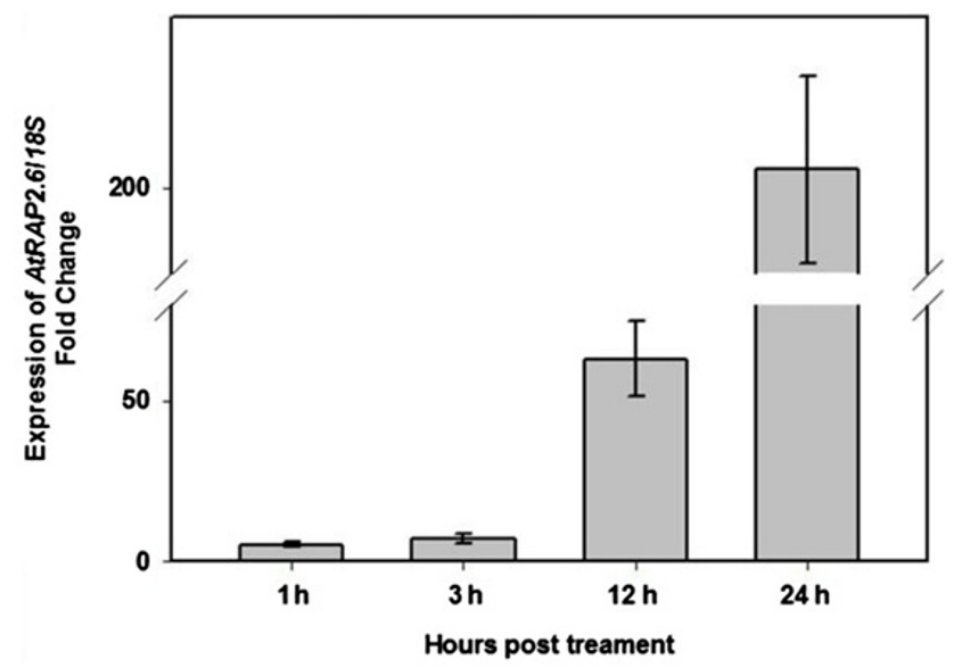

B

$3 \mathbf{h}$

$12 \mathrm{~h}$

$24 \mathrm{~h}$
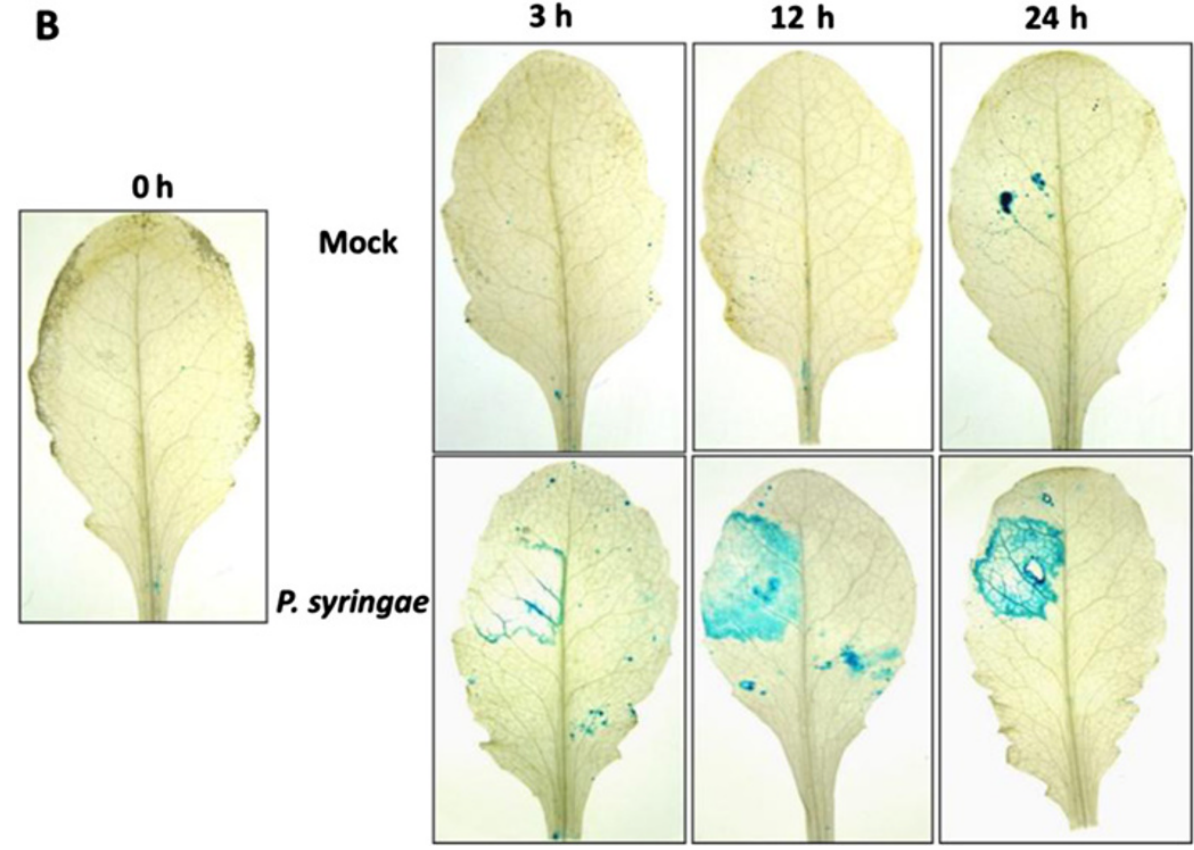

Figure 4 Expression of RAP2.6 in response to $P$. syringae pv tomato DC3000. A, Expression of RAP2.6 in wild type plants in response to $P$. syringae pv tomato DC3000 was determined by qRT-PCR. The data included three independent biological and three technical replicates. Values are means $\pm \mathrm{SE}, \mathrm{n}=3$. The bar shows standard error for the mean. B, GUS staining of rosette leaves of a promRAP2.6:GUS line after mock infiltration $\left(\mathrm{MgCl}_{2}\right)$ and infiltration with P. syringae pv tomato DC3000 at different time points.

only 7 were significantly upregulated. Besides RAP2.6, the downregulated genes included RAP2.4 (also named WIND1), which is involved in the wound response [34] and At3g50260 (DEAR1), a positive regulator of cell death and PR-gene expression [32]. Another downregulated gene was ORA59 [31], which is involved in the JAregulated resistance response. Furthermore, the transcription factors ERF5, ERF6 and to some extent ERF8 have been reported to be involved in chitin-induced resistance reactions of Arabidopsis [35]. The genes for ERF5 and
ERF6 were both significantly downregulated in syncytia. Thus, downregulated ERF genes included those for transcription factors important for the expression of resistancerelated genes, supporting the observation that $H$. schachtii downregulates the resistance response in syncytia.

A notable exception was $R A P 2.3$, which was expressed in roots and syncytia at a very high level and which was even more upregulated in syncytia as compared to roots. However, it has been shown that RAP2.3 functioned as a suppressor of cell death in yeast [36] and its upregulation 


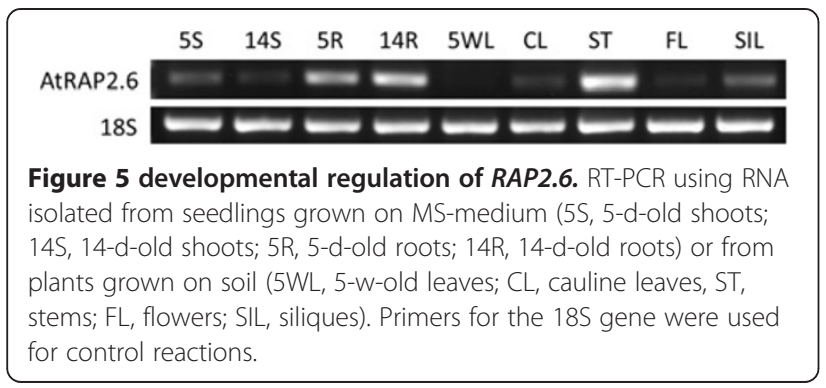

in syncytia would therefore be important to support the development of syncytia. RAP2.3 was not the focus of this work but it might be interesting to study its role for syncytium development in detail.

\section{Expression of RAP2.6}

The starting point for this work was the observation that the RAP2.6 gene was strongly downregulated in syncytia as determined by a transcriptome analysis of syncytia [16]. We have confirmed this downregulation by qRTPCR of syncytia cut out from infected roots and by analysis of a promRAP2.6::GUS line. The expression of RAP2.6 has been studied before. According to Genevestigator [37] (Additional file 3) this gene is especially expressed in protoplasts and in roots. The strongest expression in roots was in the maturation zone. Expression in inflorescences and especially rosette leaves and seedlings was found by qRT-PCR [24]. These authors also produced promoter::GUS fusions which showed expression in roots of 7-d-old seedlings, petals, carpels, and the valves of immature siliques. Our promoter::GUS line confirmed the expression in seedlings

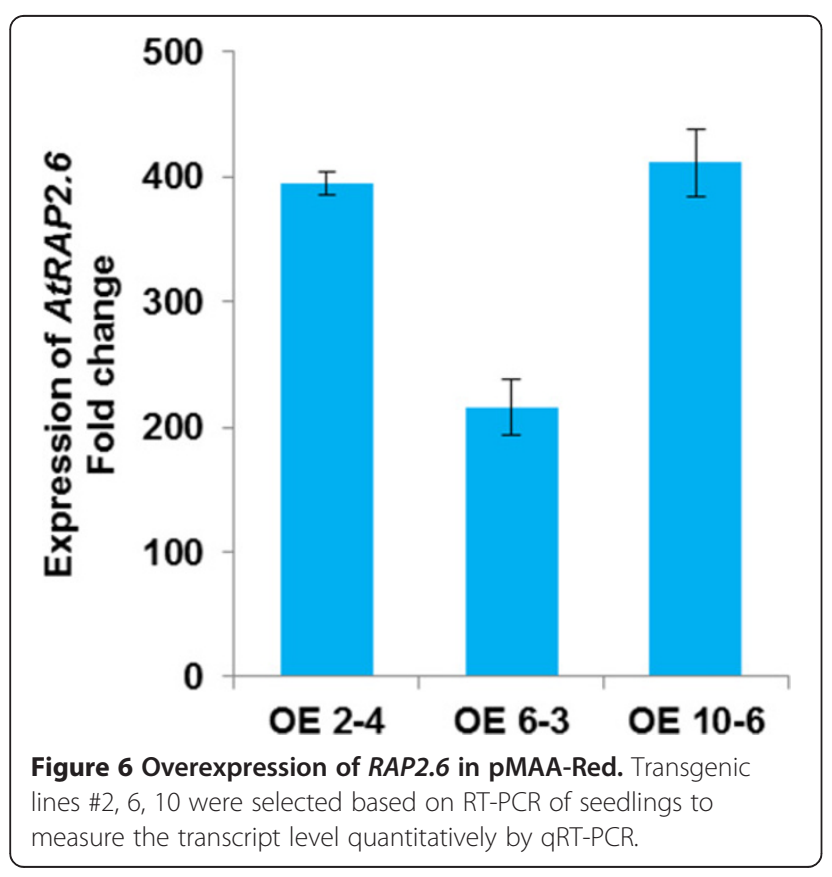

and carpels but we did not find expression in petals and the expression in the valves of siliques was weak. The reason for these differences is not known and might be related either to the promoter fragment or the specific GUS lines that were used. However, all our results, including the GUS analysis after the induction by $P$. syringae pv tomato DC3000 and the analysis of GUS expression after infection with $H$. schachtii are in line with previous observations $[16,25,27]$ and our qRT-PCR results.

\section{Transcriptional response of RAP2.6 to different stimuli/ stresses}

Induction of RAP2.6 by both JA and SA has been demonstrated [23-25]. Similarly, activation of this gene in response to ABA and various abiotic stresses such as salt, heat, drought, and osmotic stress has been reported $[23,24]$. In addition to these stresses, it seemed that $R A P 2.6$ is also inducible by wounding as indicated by our GUS analysis of induction after $P$. syringae pv tomato DC3000 infiltration where some GUS staining was observed at 24 hpi of mock infiltration.

\section{Role of RAP2.6 for nematode development}

Cyst nematodes manipulate the expression of various plant genes which leads to the development of syncytia as their sole nutrient source [38]. Defense-related genes are preferentially downregulated $[16,17]$ which might be achieved through the activity of effectors produced by the nematode and injected into the syncytium. Several recent reports support this hypothesis. Expression of the putative $H$. glycines effector $\mathrm{Hg} 30 \mathrm{C0} 2$ in Arabidopsis increased susceptibility to $H$. schachtii possibly by interfering with a plant PR-protein $[39,40]$. Furthermore, it has recently shown that Globodera rostochiensis produces an effector (SPRYSEC-19) which is able to suppress plant defense responses [41]. It is justified to assume that nematodes produce a variety of effectors (suppressors) that are involved in downregulating defense-related genes in syncytia [42]. Among such downregulated genes in syncytia [16] were for instance WRKY33 ([43], Ali et al., manuscript in preparation) and RAP2.6. RAP2.6 belongs to the large family of ethylene response factors. Many of these are transcription factors which respond to ethylene or JA stimuli. Another example is for instance ORA59 [31] which is also downregulated in syncytia [16].

Overexpression of RAP2.6 resulted in higher resistance against $H$. schachtii, supporting the consideration that downregulation of RAP2.6 in syncytia is important for compatibility. The T-DNA mutant rap2.6 did not show an effect in our resistance assays except a small effect on syncytium size. In case of $P$. syringae, bacteria are still able to induce JA-dependent pathways, thus suppressing the SA pathway which leads to a compatible interaction. In case of $H$. schachtii, the downregulation of $R A P 2.6$ by 


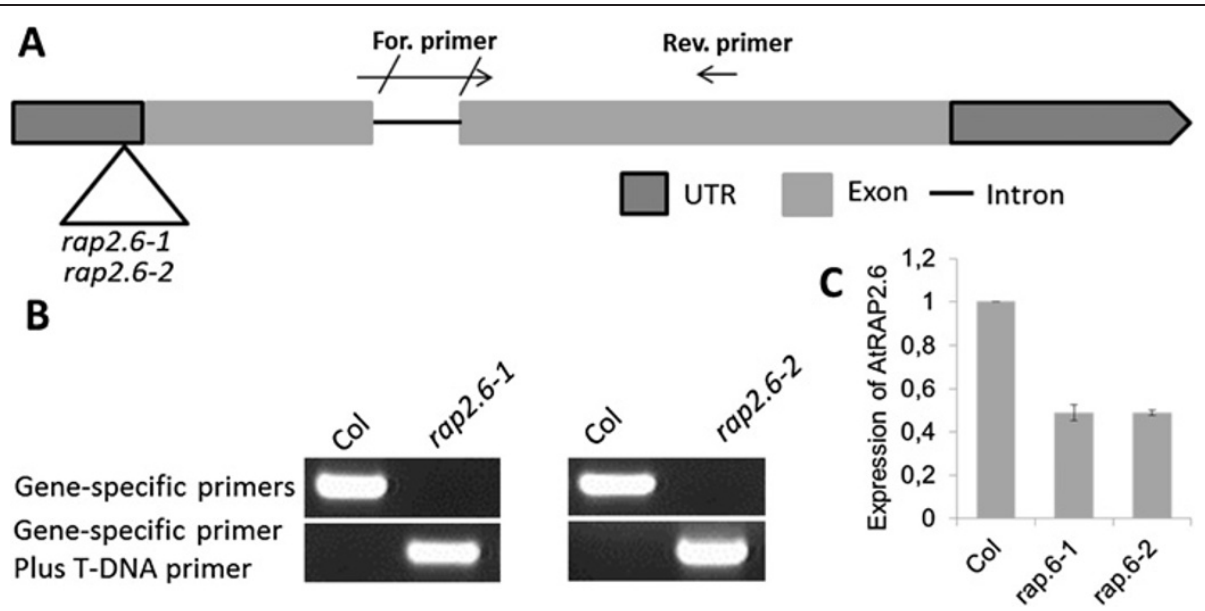

Figure 7 Knock-out mutants for RAP2.6. A: The T-DNA insertion (inverted triangle) in rap2.6-1 (GK_053G11 .01) and rap2.6-2 (GK_053G11 .02) is located in the $5^{\prime}$ UTR. B: PCR with DNA from homozygous mutants and Columbia (Col). C: qRT-PCR for measurement of the expression of mutants as compared with WT in 14-d-old seedlings. For. primer and Rev. primer indicate the positions for the forward and reverse primer used for qRT-PCR.

the nematode is obviously sufficient to completely block downstream resistance reactions and therefore the mutant did not further enhance the susceptibility.

The analysis of JA-, SA-, and ET-responsive genes indicated that the nematodes might induce an initial plant response during early infection resulting in the induction of SA-, JA-, and ET-dependent plant resistance responses. This response was elevated in the overexpression lines with the strongest enhancement found for JA-inducible genes. These results indicated that the enhanced resistance found against $H$. schachtii might be the result of JA-dependent reaction mechanisms. Induction of PR genes in Arabidopsis roots after H. schachtii infection has been reported before [40]. It has been suggested that cyst nematodes suppress SA-dependent resistance at their feeding sites [44]. The JA pathway was found to be important for resistance of rice against root

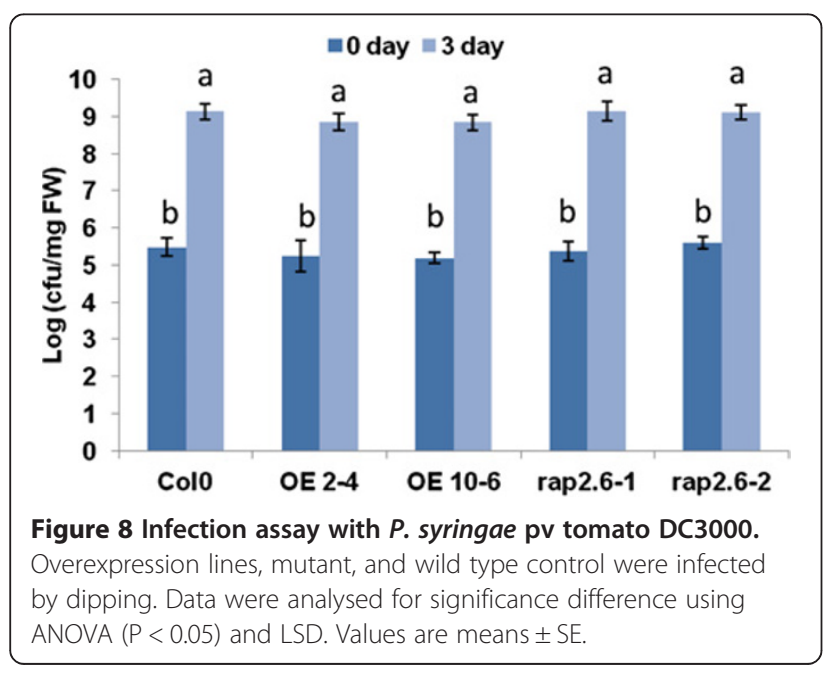

knot nematodes [45] but nothing is known about JAdependent signaling in Arabidopsis roots infected with $H$. schachtii except that defense-related genes including those dependent on JA-signaling are downregulated in syncytia [16]. At the moment we do not know for sure if the enhanced resistance of RAP2.6 overexpression lines is a consequence of the expression of JA-dependent defense genes or due to enhanced callose deposition (or both). However, considering that the induction of JAdependent defense genes was only found at very early time points makes it very likely that the enhanced callose deposition was the main reason for the resistance of the overexpression lines.

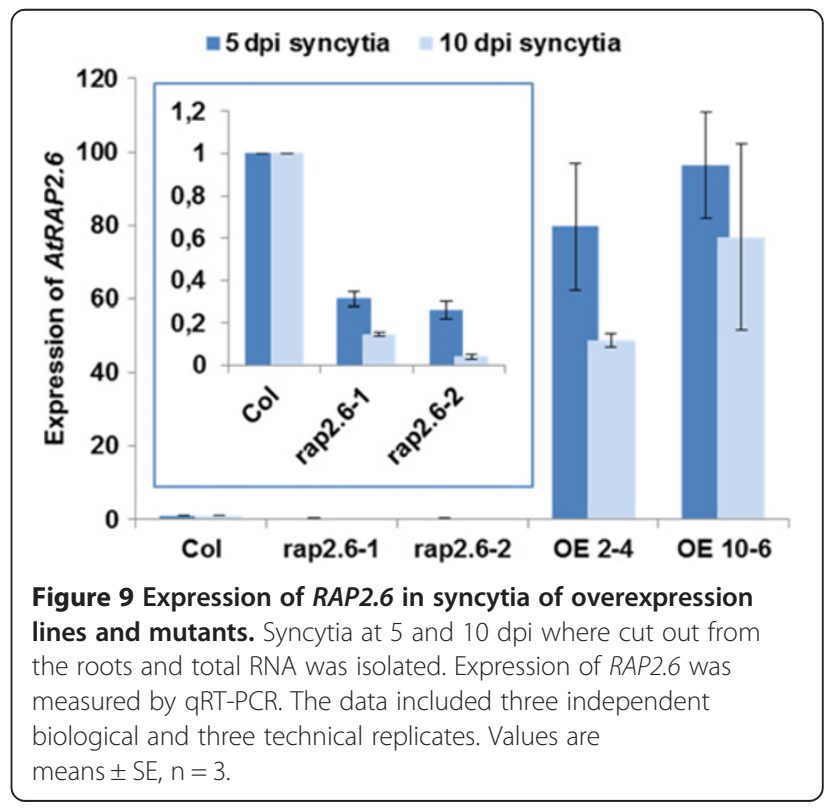




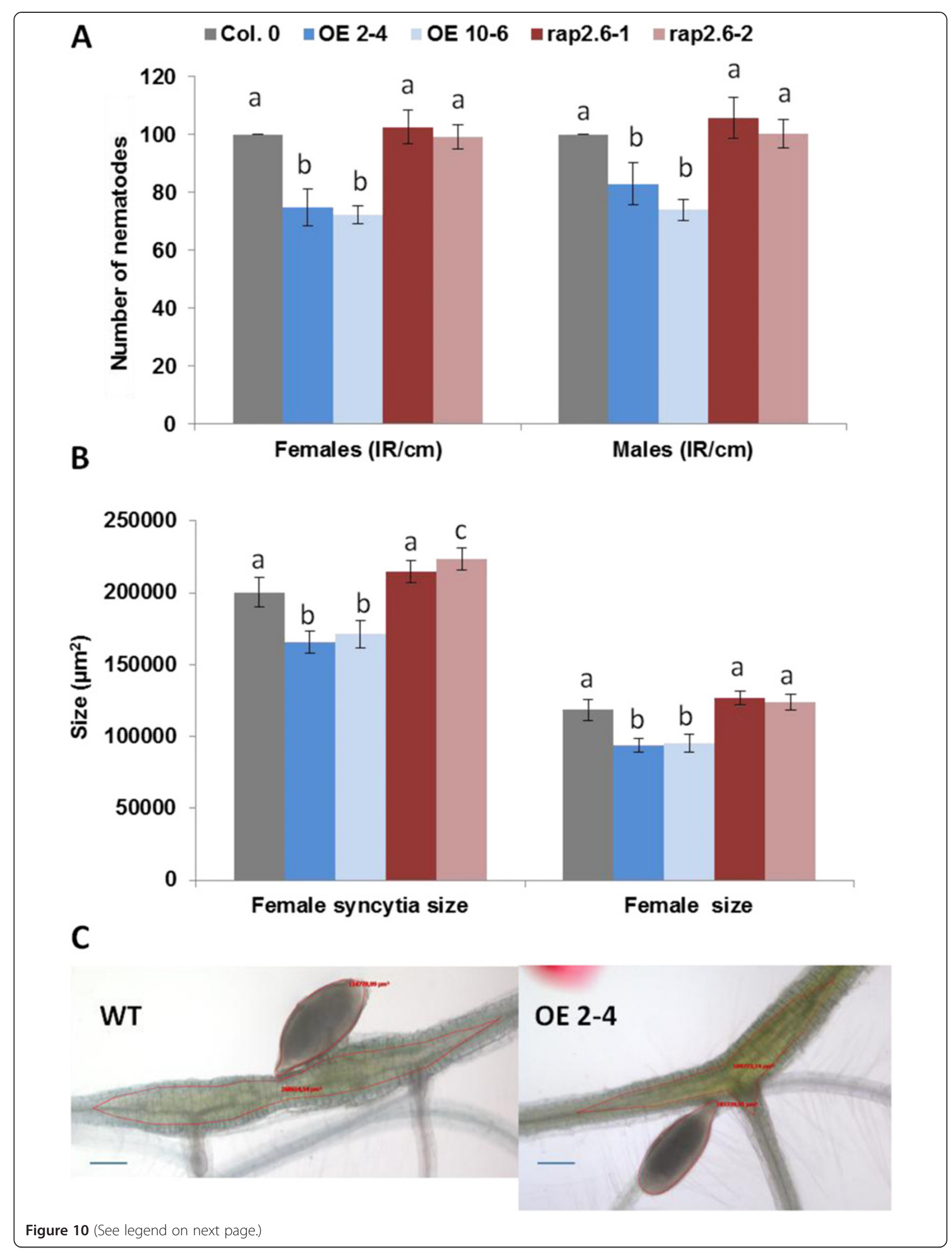


(See figure on previous page.)

Figure 10 Nematode resistance test. The resistance of overexpression lines and knock-out mutants of RAP2.6 was compared to wild type plants after infection with $\mathrm{H}$. schachtii. A: Number of male and female nematodes per $\mathrm{cm}$ of root length calculated at $15 \mathrm{dpi}$ setting the wild type as $100 \%$. The statistical significance was determined by three independent replicates. Values are means $\pm S E, n=15$. The bar shows standard error for the mean and different letters indicate significante differences ( $P<0.05$; ANOVA and LSD). B: Size of female syncytia and female nematodes at $14 \mathrm{dpi}$. Ten syncytia were selected randomly from three independent replicates (total $=30$ ) and the size of syncytia and associated female nematodes was determined. Data were analysed for significance difference using ANOVA $(P<0.05)$ and LSD. Values are means \pm SE. C: Representive pictures of the photographed syncytia and nematodes from wild type Col and overexpression line OE 2-4. Scale bar (blue) $=100 \mu \mathrm{m}$.

Callose deposition is known as a plant resistance response to invading pathogens [46]. This reaction is also increasingly used to quantify the reaction to bacterial PAMPs (Pathogen Associate Molecular Patterns) such as flagellin (see for instance [47]. Callose deposition is also one of the earliest plant responses to invading nematodes $[48,49]$. The degradation of callose deposited outside of the cell membranes in the plant roots is important for nematode development [50]. However, nothing is known about the role of callose in plant resistance against nematodes although it could be imagined that callose might be used to plug the plasmodesmata between syncytia and phloem cells [51]. It is for instance known that resistant rice plants plug the sieve plates with callose in response to feeding of the brown planthopper [52].

\section{Conclusion}

Our results showed that overexpression of RAP2.6 led to enhanced callose deposits in syncytia. Callose deposition at syncytium plasmodesmata would disturb nutrient import into syncytia and would inhibit the development of the nematodes since these are dependent on nutrients supplied through syncytia. It would therefore be interesting to further explore the role of callose in resistance against cyst nematodes in more detail.

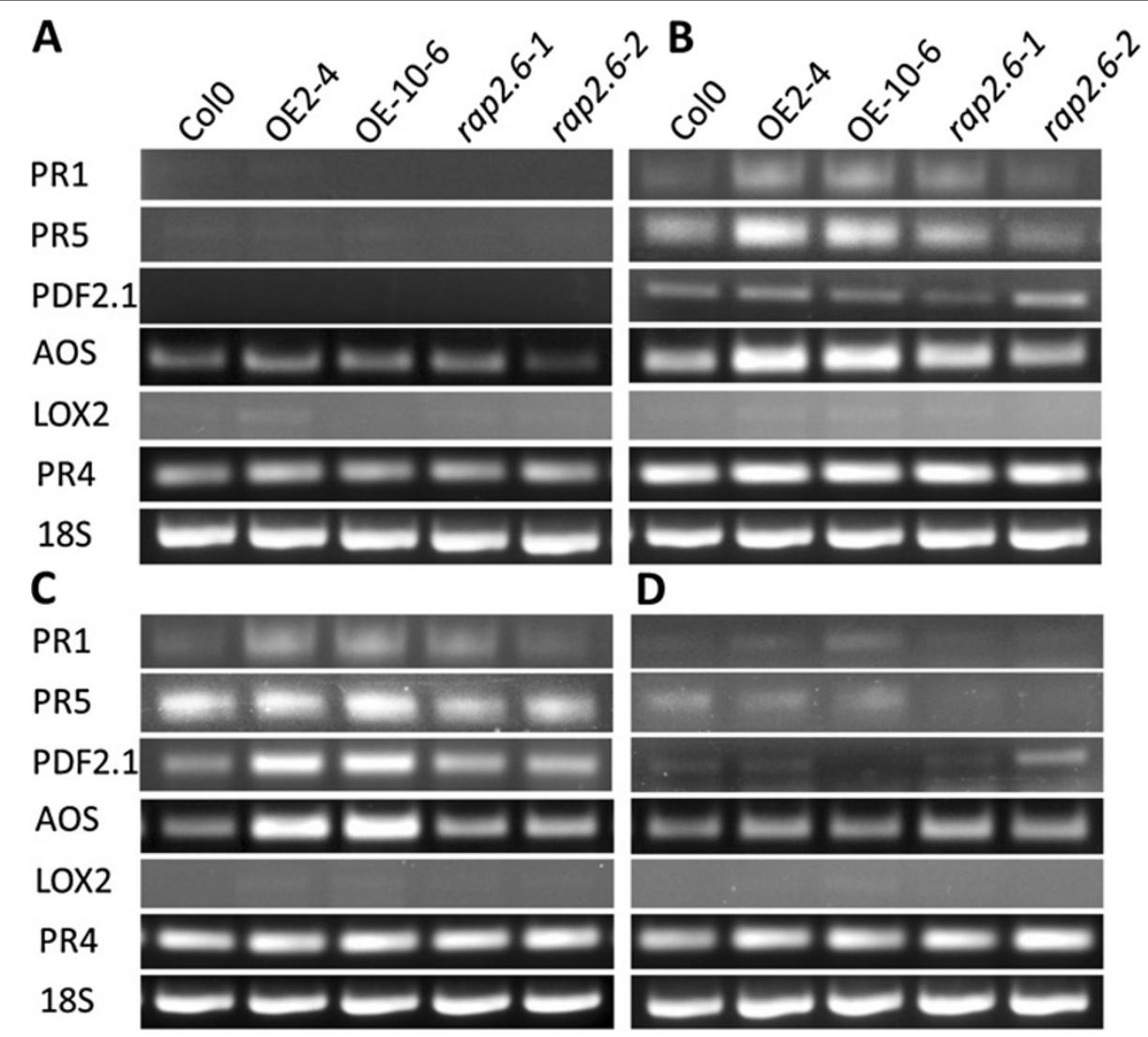

Figure 11 Expression of different JA and SA inducible genes in overexpression lines and mutant in response to nematode infection. A: uninfected root, B: 1 dpi root segments, C: 2 dpi root segments and $\mathbf{D}: 5$ dpi syncytia. 


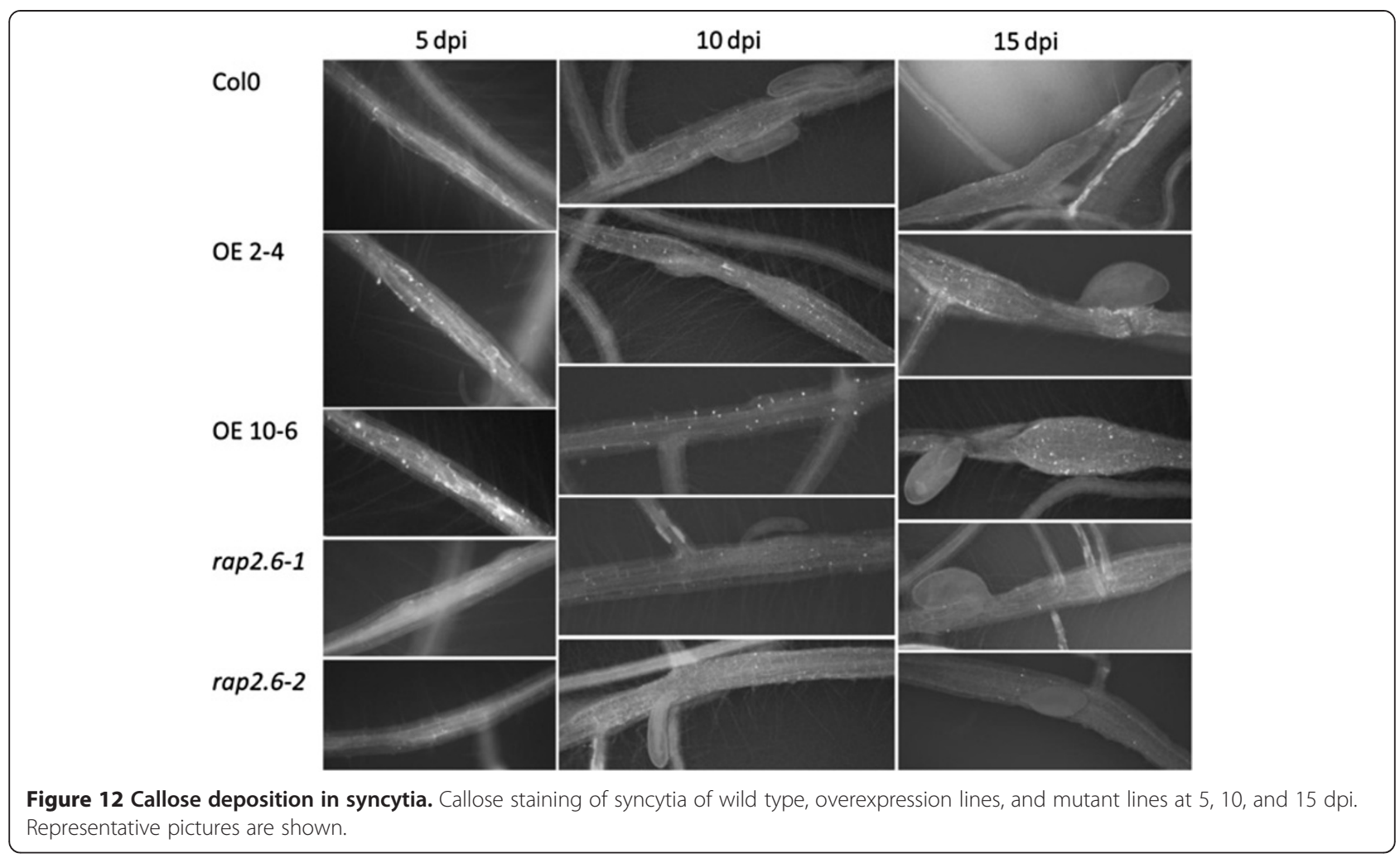

\section{Methods}

\section{Plant cultivation}

Arabidopsis (ecotype Columbia) plants were grown in soil in growth chambers at $25^{\circ} \mathrm{C}$ in long day conditions (16 h light / $8 \mathrm{~h}$ dark). For growth in sterile conditions, seeds were surface sterilized for $7 \mathrm{~min}$ in $10 \%(\mathrm{w} / \mathrm{v})$ sodium hypochlorite and subsequently washed three times with sterile water. Seeds were placed in Petri dishes $(9 \mathrm{~cm})$ on a modified Knop medium with $2 \%$ sucrose [53] or on MS medium containing 3\% sucrose [54].

\section{Production of promoter::GUS and overexpression lines}

The promoter region $1333 \mathrm{bp}$ upstream the start codon of the RAP2.6 gene (At1g43160) was amplified by PCR (Phusion High-Fidelity DNA Polymerase from Thermo Scientific) using $50 \mathrm{ng}$ Arabidopsis Columbia genomic DNA as template. The primer pair used for amplification of the promoter region were promRAP2.6forEcoRI and promRAP2.6revNcoI (Additional file 4). Primers included restriction sites for EcoRI and NcoI for subsequent cloning into the binary vector pMAA-Red [33]. This plasmid harbors the DsRed gene for plant selection. It also contains the double enhanced $35 \mathrm{~S}$ promoter of the cauliflower mosaic virus (CaMV) and TMV omega element as translational enhancer fused to the GUS reporter. During the cloning procedure the $35 \mathrm{~S}$ promoter was exchanged by the promoter fragment of $R A P 2.6$. For construction of overexpression lines a cDNA clone for RAP2.6 (RIKEN, Japan, http://www. riken.go.jp) was used as template. The cDNA was amplified by PCR using Phusion polymerase with RAP2.6forBspHI and RAP2.6revBamHI primers (Additional file 4). The primers included the BspHI and BamHI restriction sites for subsequent cloning into the binary vector pMAA-Red, this time replacing the GUS gene.

The promoter::GUS and overexpression constructs were introduced into Agrobacterium tumefaciens GV3101 for

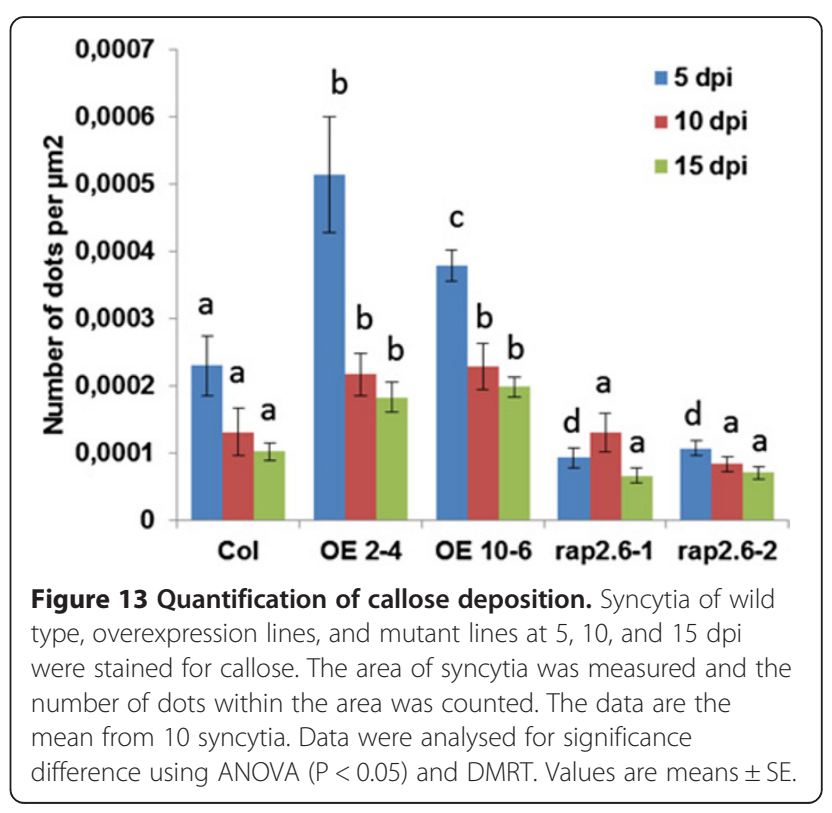


transformation of Arabidopsis plants by the floral dip method [55]. The fluorescent transformed seeds were selected under an inverse microscope equipped with a DsRed fluorescence filter (Axiovert 200M; Zeiss AG, Germany) and put on soil to grow the next generation. Homozygous lines were selected based on visual observation as described [33].

\section{Mutant screening}

Two independent lines from a single knockout mutant of RAP2.6 were obtained from the Arabidopsis stock center (GK_053G11.01 with stock number N301757 for rap2.6-1 and GK_053G11.02 with stock number N301758 for rap2.6-2) (Figure 6). These are individual T3 seed lines for the parental line GK-053G11. The DNA of different segregating plants of each line was isolated [56] and PCR analysis (Gk-Lb primer and primer pairs used for screening of single mutants are shown in Additional file 4) was used to identify homozygous knockouts.

\section{Nematode infection assays}

$H$. schachtii cysts were harvested from in vitro stock cultures propagated on mustard (Sinapsis alba cv Albatros) roots growing on 0.2 concentrated Knop medium supplemented with $2 \%$ sucrose [53]. The cysts were soaked in $3 \mathrm{mM} \mathrm{ZnCl}_{2}$ as stimulus for hatching of $\mathrm{J} 2$ larvae under sterile conditions. The J2 larvae were then washed three times in sterile water and resuspended in $0.5 \%$ (w/v) Gelrite (Duchefa, Haarlem, The Netherlands) before inoculation. Twelve-d-old Arabidopsis roots were inoculated under sterile conditions with about 50-60 juveniles per plant. At $14 \mathrm{dpi}$, pictures of female syncytia and female nematodes (longitudinal optical sections) were taken using an inverse microscope (Axiovert 200M; Zeiss AG, Germany). The syncytia and females were outlined using the Axiovision Kontour tool (Zeiss AG, Germany) and the area was determined by the software. Afterwards, the number of males and females per $\mathrm{cm}$ of root length was counted at $15 \mathrm{dpi}$. Root length was scored according to [57] by comparing the roots growing on agar plates with pictures for the different classes of root growth. The data regarding number of nematodes and sizes of nematodes and syncytia were analysed using single factor ANOVA $(\mathrm{P}<0.05)$. As the F-statistic was greater than $\mathrm{F}$ critical, a Least Significance Test (LSD) was applied.

\section{GUS analysis}

Histochemical detection of GUS activity was performed by staining using X-gluc (Biomol, Hamburg, Germany) in $0.1 \mathrm{M}$ sodium phosphate buffer $\mathrm{pH} 7.0,0.1 \%$ Triton$\mathrm{X} 100,0.5 \mathrm{mM} \mathrm{K}_{3}\left[\mathrm{Fe}(\mathrm{CN})_{6}\right], 0.5 \mathrm{mM} \mathrm{K}_{4}\left[\mathrm{Fe}(\mathrm{CN})_{6}\right]$ and $10 \mathrm{mM} \mathrm{Na} \mathrm{NaDTA}_{2}$. For GUS staining of syncytia, the infected roots (infection was done as described above) of promRAP2.6::GUS plants were incubated with X-gluc overnight at $37^{\circ} \mathrm{C}$. The staining was examined at $1,3,5$, 7, 10, and 15 dpi. Stained syncytia and uninfected roots were photographed under an inverse microscope (Axiovert 200M; Zeiss, Hallerbergmoos, Germany) having an integrated camera (AxioCam MRc5; Zeiss).

\section{RNA isolation}

Plant samples were immediately frozen in liquid nitrogen. Total RNA was isolated using a NucleoSpin ${ }^{\circledR}$ RNA Plant kit (genXpress) according to the manufacturer's instructions, including DNase digestion. However, this DNase treatment did not completely digest the DNA present in the sample. For some experiments the remaining DNA was therefore digested using Ambion ${ }^{\circledR}$ DNA-free ${ }^{\mathrm{TM}}$ DNase Treatment and Removal Reagents (Invitrogen). RNA was quantified using NanoDrop (NanoDrop ${ }^{\mathrm{TM}}$ 2000c from PEQLAB). Isolated RNA was stored immediately at $-80^{\circ} \mathrm{C}$.

\section{Reverse Transcriptase (RT-PCR) and quantitative Real Time PCR (qRT-PCR)}

RT-PCR was done using the RT-PCR Master Mix (USB) following the manufacturer's instructions. For cDNA synthesis Superscript III reverse transcriptase (Invitrogen) and random primers (oligo $(\mathrm{dN}) 6$ ) according to the manufactures instructions were used. The qRT-PCR was performed on an ABI PRISM 7300 Sequence Detector (Applied BioSystems). Each qRT-PCR sample contained $12.5 \mu$ Platinum SYBR Green qPCR SuperMix with UDG and ROX (Invitrogen), $2 \mathrm{mM} \mathrm{MgCl}, 0.5 \mu \mathrm{l}$ forward and reverse primer $(10 \mu \mathrm{M}), 2 \mu \mathrm{l}$ cDNA and water to make a $25 \mu \mathrm{l}$ total reaction volume. The primer pairs used for RAP2.6 were RAP2.6qRTfor and RAP2.6qRTrev which are given in Additional file 4. Control reactions with no cDNA template ruled out false positives. Dissociation runs were performed to make sure that there was no formation of primer dimers. The $18 \mathrm{~S}$ gene was used as an internal reference. Results were calculated using the Sequence Detection Software SDS v2.0 (Applied BioSystems). Relative expression was calculated by the $(1+E)^{-\Delta \Delta C t}$ method [58].

\section{Callose staining of syncytia}

Nematode infection of wild type, overexpression lines, and knockout mutants was carried out as described above. At 5,10 , and 15 dpi syncytia were stained for callose deposition as described by Millet et al. [47] with some modifications. The syncytia were fixed in a 3:1 ethanol:acetic acid solution for $4 \mathrm{~h}$. The fixative was changed after two hours for thorough fixing and clearing of the tissues for good callose detection. Syncytia were rehydrated in 30\% ethanol for $3 \mathrm{~h}$ and water overnight. After three water washes, seedlings were treated with $10 \% \mathrm{NaOH}$ and placed at $37^{\circ} \mathrm{C}$ for $1 \mathrm{~h}$ to make the tissues transparent. After four water washes, the syncytia were incubated at room temperature in $150 \mathrm{mM} \mathrm{K} \mathrm{KPO}_{4}, \mathrm{pH}$ 9.5, and $0.01 \%$ aniline blue 
(Sigma-Aldrich) for 2 hours. The callose was observed immediately using an inverse microscope (Axiovert 200M; Zeiss, Hallerbergmoos, Germany) with integrated camera (AxioCam MRc5; Zeiss) under UV (excitation, $390 \mathrm{~nm}$; emission, $460 \mathrm{~nm}$ ). The callose deposition was quantified per unit area basis. For this the area of the syncytia was measured and dots within the area were counted.

\section{Pseudomonas syringae infection assay}

The infection assay was carried out according to Tornero and Dangl [59] with some modifications using the pathogenic strain Pseudomonas syringae pv tomato DC3000. Approximately $24 \mathrm{~h}$ prior to inoculation, and in order to obtain a lawn of bacteria, a bacterial inoculum was distributed onto fresh King's B-medium plates and incubated for $24 \mathrm{~h}$ at $28^{\circ} \mathrm{C}$. Then, $15 \mathrm{ml}$ of $10 \mathrm{mM} \mathrm{MgCl}_{2}$ was added to the plates to scrape of the bacterial lawn and resuspended in a falcon tube. A bacterial pellet was obtained after centrifugation at $4000 \mathrm{rpm}$ for $10 \mathrm{~min}$ and resuspended again in $10 \mathrm{mM} \mathrm{MgCl}$. The bacterial suspension was diluted to an $\mathrm{OD}_{600}$ of 0.05 with $10 \mathrm{mM} \mathrm{MgCl}$ and silwet was added to a final concentration of $200 \mu \mathrm{l} / \mathrm{L}$. Pots with Arabidopsis plants (15-d-old seedlings) were then turned upside down, dipped in the bacterial suspension and swirled for 10 seconds. After infection, the plants were covered with a transparent lid and moved back to the growth chamber.

One hour after the inoculation, and for each investigated line, around 50-100 mg of infected seedlings (only aerial parts) were transferred into a pre-weighed $1.5 \mathrm{ml}$ tube containing $200 \mu \mathrm{l}$ of $10 \mathrm{mM} \mathrm{MgCl}_{2}$ and $200 \mu \mathrm{l} / \mathrm{L}$ silwet. The tubes were shaken $(250 \mathrm{rpm})$ in a 2 litre Erlenmeyer for one hour at $28^{\circ} \mathrm{C}$. After that, $20 \mu \mathrm{l}$ from each tube were added to a 96-well plate containing 180 $\mu \mathrm{l}$ of $10 \mathrm{mM} \mathrm{MgCl}_{2}$ (without silwet). By using a multichannel pipette, serial 10-fold dilutions from the bacterial suspension were prepared, spotted onto fresh King'sB medium plates and incubated for 24 hours at $28^{\circ} \mathrm{C}$. The numbers of colonies were counted to determine the colony forming unit (CFU) per unit fresh weight. The CFU data $\left(\log _{10}\right)$ for $0 \mathrm{dpi}$ and $3 \mathrm{dpi}$ were calculated using the CFU equation given by Tornero and Dangl [59].

For GUS staining, the promRAP2.6::GUS line was grown on soil in short day conditions and after 5 weeks rosette leaves were mock infiltrated with $\mathrm{MgCl}_{2}$ or infiltrated with $P$. syringae. The staining was done at $0,3,12$ and $24 \mathrm{~h}$ with X-Gluc for 8 hours at $37^{\circ} \mathrm{C}$.

\section{Statistical analysis of microarray data}

Affymetrix CEL files from Szakasits et al. [16] were analyzed using packages of the Bioconductor suite (www. bioconductor.org). For details see Szakasits et al. [16]. For the statistical tests, individual gene variances have been moderated using an Empirical Bayes approach as described in Siddique et al. [17] and in the online methods (Additional file 5). Tests were restricted to the subset of 105 genes of the 122 ERF group genes that could be probed on the GeneChip, with the group as defined before [20] and containing the originally described RAP2 proteins as different subgroups. This considerably increases the statistical power of the testing procedure as it reduces the necessary correction for otherwise massive multiple testing.

\section{Additional files}

Additional file 1: MA plot (syncytium vs. root) for ERF genes.

Additional file 2: MA plot (15 dpi syncytium vs. 5 dpi syncytium) for ERF genes.

Additional file 3: Gene expression of RAP2.6 according to Genevestigator.

Additional file 4: Primers used in this work.

Additional file 5: Online methods bioinformatic analysis.

\section{Competing interests}

The authors declare that they have no competing interests.

\section{Authors' contributions}

MAA carried out most of the experiments and helped writing the manuscript. AA did the Pseudomonas experiments. DK did the bioinformatics analysis. HB conceived of the study, and participated in its design and coordination, was involved in analyzing the experiments and writing the manuscript. All authors read and approved the final manuscript.

\section{Acknowledgements}

We appreciate the excellent technical assistance of Sabine Daxböck-Horvath and Martina Niese. This research was supported by grants P16296-B06 and P20471-B11 of the Austrian Science Fund (FWF). Muhammad Amjad Ali and Amjad Abbas were supported by Higher Education Commission (HEC) of Pakistan. DPK gratefully acknowledges support by the Vienna Science and Technology Fund (WWTF), Baxter AG, Austrian Institute of Technology (AIT), and the Austrian Centre of Biopharmaceutical Technology (ACBT).

\section{Author details}

'Division of Plant Protection, Department of Crop Sciences, University of Natural Resources and Life Sciences Vienna, UFT Tulln, Konrad Lorenz Str. 24, 3430, Tulln, Austria. ${ }^{2}$ Current address: Department of Bioinformatics and Biotechnology, GC University, Faisalabad, Pakistan. ${ }^{3}$ Chair of Bioinformatics, Department of Biotechnology, University of Natural Resources and Life Sciences Vienna, Vienna, Austria. ${ }^{4}$ School of Life Sciences, University of Warwick, Warwick, UK.

Received: 22 November 2012 Accepted: 7 March 2013 Published: 19 March 2013

\section{References}

1. Blaxter ML, De Ley P, Garey JR, Liu LX, Scheldeman P, Vierstraete A, Vanfleteren JR, Mackey LY, Dorris M, Frisse LM, et al: A molecular evolutionary framework for the phylum Nematoda. Nature 1998, 392(6671):71-75.

2. Abad P, Gouzy J, Aury JM, Castagnone-Sereno P, Danchin EGJ, Deleury E, Perfus-Barbeoch L, Anthouard V, Artiguenave F, Blok VC, et al: Genome sequence of the metazoan plant-parasitic nematode Meloidogyne incognita. Nat Biotechnol 2008, 26(8):909-915.

3. Hussey RS, Grundler FM: Nematode parasitism of plants. In The Physiology and Biochemistry of Free-living and Plant-parasitic nematodes. vol. 1st edition. Edited by Perry RN, Wright DJ. CAB International: CAB International; 1998:213-243.

4. Wyss $U$, Zunke $U$ : Observations on the behaviour of second stage juveniles of Heterodera schachtii inside host roots. Revue de Nématologie 1986, 9(2):153-165. 
5. Jones MGK, Payne HL: Early stage of nematode-induced giant-cell formation in roots of Impatiens balsamina. J Nematol 1978, 10(1):70-84.

6. Jones MGK: Host cell responses to endoparasitic nematode attack: structure and function of giant cells and syncytia. Ann Appl Biol 1981, 97(3):353-372

7. Golinowski W, Grundler FMW, Sobczak M: Changes in the structure of Arabidopsis thaliana during female development of the plant-parasitic nematode Heterodera schachtii. Protoplasma 1996, 194(1-2):103-116.

8. Wyss U, Grundler FMW: Heterodera-Schachtii and Arabidopsis-Thaliana, a Model Host-Parasite Interaction. Nematologica 1992, 38(4):488-493.

9. Goellner M, Wang XH, Davis EL: Endo-beta-1,4-glucanase expression in compatible plant-nematode interactions. Plant Cell 2001, 13(10):2241-2255

10. Wieczorek K, Golecki B, Gerdes L, Heinen P, Szakasits D, Durachko DM, Cosgrove DJ, Kreil DP, Puzio PS, Bohlmann $H$, et al: Expansins are involved in the formation of nematode-induced syncytia in roots of Arabidopsis thaliana. Plant J 2006, 48(1):98-112.

11. Wieczorek K, Hofmann J, Blochl A, Szakasits D, Bohlmann H, Grundler FMW: Arabidopsis endo-1,4-beta-glucanases are involved in the formation of root syncytia induced by Heterodera schachtii. Plant J 2008, 53(2):336-351.

12. Endo B: Ultrastructure of initial responses of susceptible and resistant soybean roots to infection by Heterodera glycines. Revue de Nematologie 1991, 14(1):73-94.

13. Grundler FMW, Sobczak M, Lange S: Defence responses of Arabidopsis thaliana during invasion and feeding site induction by the plantparasitic nematode Heterodera glycines. Physiol Mol Plant P 1997, 50(6):419-429.

14. Davis EL, Hussey RS, Baum TJ: Getting to the roots of parasitism by nematodes. Trends Parasitol 2004, 20(3):134-141.

15. Davis EL, Mitchum MG: Nematodes, Sophisticated parasites of legumes. Plant Physiol 2005, 137(4):1182-1188.

16. Szakasits D, Heinen P, Wieczorek K, Hofmann J, Wagner F, Kreil DP, Sykacek $P$, Grundler FM, Bohlmann H: The transcriptome of syncytia induced by the cyst nematode Heterodera schachtii in Arabidopsis roots. Plant J 2009, 57(5):771-784

17. Siddique S, Endres S, Atkins JM, Szakasits D, Wieczorek K, Hofmann J, Blaukopf C, Urwin PE, Tenhaken R, Grundler FMW, et al: Myo-inositol oxygenase genes are involved in the development of syncytia induced by Heterodera schachtii in Arabidopsis roots. New Phytol 2009, 184(2):457-472

18. Okamuro JK, Caster B, Villarroel R, Van Montagu M, Jofuku KD: The AP2 domain of APETALA2 defines a large new family of DNA binding proteins in Arabidopsis. P Natl Acad Sci USA 1997, 94(13):7076-7081.

19. Ohme-Takagi $M$, Shinshi H: Ethylene-Inducible DNA-Binding Proteins That Interact with an Ethylene-Responsive Element. Plant Cell 1995, 7(2):173-182.

20. Nakano T, Suzuki K, Fujimura T, Shinshi H: Genome-wide analysis of the ERF gene family in Arabidopsis and rice. Plant Physiol 2006, 140(2):411-432.

21. Chen WQ, Provart NJ, Glazebrook J, Katagiri F, Chang HS, Eulgem T, Mauch F, Luan S, Zou GZ, Whitham SA, et al: Expression profile matrix of Arabidopsis transcription factor genes suggests their putative functions in response to environmental stresses. Plant Cell 2002, 14(3):559-574.

22. Fowler S, Thomashow MF: Arabidopsis transcriptome profiling indicates that multiple regulatory pathways are activated during cold acclimation in addition to the CBF cold response pathway. Plant Cell 2002, 14(8):1675-1690

23. Zhu Q, Zhang JT, Gao XS, Tong JH, Xiao LT, Li WB, Zhang HX: The Arabidopsis AP2/ERF transcription factor RAP2.6 participates in ABA, salt and osmotic stress responses. Gene 2010, 457(1-2):1-12.

24. Krishnaswamy S, Verma S, Rahman MH, Kav NNV: Functional characterization of four APETALA2-family genes (RAP2.6, RAP2.6L, DREB19 and DREB26) in Arabidopsis. Plant Mol Biol 2011, 75(1-2):107-127.

25. He P, Chintamanani S, Chen ZY, Zhu LH, Kunkel BN, Alfano JR, Tang XY, Zhou JM: Activation of a COI1-dependent pathway in Arabidopsis by Pseudomonas syringae type III effectors and coronatine. Plant J 2004, 37(4):589-602

26. Wang Z, Cao GG, Wang XL, Miao J, Liu XT, Chen ZL, Qu LJ, Gu HG: Identification and characterization of COI1-dependent transcription factor genes involved in JA-mediated response to wounding in Arabidopsis plants. Plant Cell Rep 2008, 27(1):125-135.
27. Chen H, Pan J, Zhao X, Zhou J, Cai R: Reporter-based screen for Arabidopsis mutants compromised in nonhost resistance. Chinese Sci Bull 2008, 53(7):1027-1034.

28. Brooks DM, Bender CL, Kunkel BN: The Pseudomonas syringae phytotoxin coronatine promotes virulence by overcoming salicylic acid-dependent defences in Arabidopsis thaliana. Mol Plant Pathol 2005, 6(6):629-639.

29. Ehlting J, Chowrira SG, Mattheus N, Aeschliman DS, Arimura G, Bohlmann J: Comparative transcriptome analysis of Arabidopsis thaliana infested by diamond back moth (Plutella xylostella) larvae reveals signatures of stress response, secondary metabolism, and signalling. BMC Genomics 2008, 9:154.

30. Atallah M: Jasmonate-responsive AP2-domain transcription factors in Arabidopsis. Leiden, The Netherlands: University of Leiden; 2005.

31. Pre M, Atallah M, Champion A, De Vos M, Pieterse CM, Memelink J: The AP2/ERF domain transcription factor ORA59 integrates jasmonic acid and ethylene signals in plant defense. Plant Physio/ 2008, 147(3):1347-1357.

32. Tsutsui T, Kato W, Asada Y, Sako K, Sato T, Sonoda Y, Kidokoro S, Yamaguchi-Shinozaki K, Tamaoki M, Arakawa K, et al: DEAR1, a transcriptional repressor of DREB protein that mediates plant defense and freezing stress responses in Arabidopsis. J Plant Res 2009 122(6):633-643.

33. Ali MA, Shah KH, Bohlmann H: pMAA-Red: a new pPZP-derived vector for fast visual screening of transgenic Arabidopsis plants at the seed stage. BMC Biotechnol 2012, 12(1):37

34. Iwase A, Mitsuda N, Koyama T, Hiratsu K, Kojima M, Arai T, Inoue Y, Seki M, Sakakibara H, Sugimoto K, et al: The AP2/ERF Transcription Factor WIND1 Controls Cell Dedifferentiation in Arabidopsis. Curr Biol 2011, 21(6):508-514

35. Son GH, Wan JR, Kim HJ, Nguyen XC, Chung WS, Hong JC, Stacey G: EthyleneResponsive Element-Binding Factor 5, ERF5, Is Involved in Chitin-Induced Innate Immunity Response. Mol Plant Microbe In 2012, 25(1):48-60.

36. Ogawa T, Pan L, Kawai-Yamada M, Yu LH, Yamamura S, Koyama T, Kitajima S, Ohme-Takagi M, Sato F, Uchimiya H: Functional analysis of Arabidopsis ethylene-responsive element binding protein conferring resistance to Bax and abiotic stress-induced plant cell death. Plant Physiol 2005 138(3):1436-1445.

37. Zimmermann P, Hirsch-Hoffmann M, Hennig L, Gruissem W: GENEVESTIGATOR, Arabidopsis microarray database and analysis toolbox. Plant Physiol 2004, 136(1):2621-2632.

38. Gheysen G, Mitchum MG: How nematodes manipulate plant development pathways for infection. Curr Opin Plant Biol 2011, 14(4):415-421

39. Hamamouch N, Li C, Hewezi T, Baum TJ, Mitchum MG, Hussey RS, Vodkin LO, Davis EL: The interaction of the novel $30 \mathrm{C0} 2$ cyst nematode effector protein with a plant beta-1,3-endoglucanase may suppress host defence to promote parasitism. J Exp Bot 2012, 63(10):3683-3695.

40. Hamamouch N, Li CY, Seo PJ, Park CM, Davis EL: Expression of Arabidopsis pathogenesis-related genes during nematode infection. Mol Plant Pathol 2011, 12(4):355-364.

41. Postma WJ, Slootweg EJ, Rehman S, Finkers-Tomczak A, Tytgat TO, van Gelderen K, Lozano-Torres JL, Roosien J, Pomp R, van Schaik C, et al: The effector SPRYSEC-19 of Globodera rostochiensis suppresses CC-NB-LRRmediated disease resistance in plants. Plant Physiol 2012, 160(2):944-954

42. Hewezi T, Baum T: Manipulation of Plant Cells by Cyst and Root-Knot Nematode Effectors. Mol Plant Microbe Interact 2013, 26(1):9-16.

43. Birkenbihl RP, Diezel C, Somssich IE: Arabidopsis WRKY33 Is a Key Transcriptional Regulator of Hormonal and Metabolic Responses toward Botrytis cinerea Infection. Plant Physiol 2012, 159(1):266-285

44. Wubben MJE, Jin J, Baum TJ: Cyst nematode parasitism of Arabidopsis thaliana is inhibited by salicylic acid (SA) and elicits uncoupled SAindependent pathogenesis-related gene expression in roots. Mol Plant Microbe In 2008, 21(4):424-432.

45. Nahar K, Kyndt T, De Vleesschauwer D, Hofte M, Gheysen G: The Jasmonate Pathway Is a Key Player in Systemically Induced Defense against Root Knot Nematodes in Rice. Plant Physiol 2011, 157(1):305-316.

46. Luna E, Pastor V, Robert J, Flors V, Mauch-Mani B, Ton J: Callose Deposition: A Multifaceted Plant Defense Response. Mol Plant Microbe In 2011, 24(2):183-193.

47. Millet YA, Danna CH, Clay NK, Songnuan W, Simon MD, Werck-Reichhart D, Ausubel FM: Innate immune responses activated in Arabidopsis roots by microbe-associated molecular patterns. Plant Cell 2010, 22(3):973-990. 
48. Hussey RS, Mims CW, Westcott SW: Immunocytochemical Localization of Callose in Root Cortical-Cells Parasitized by the Ring Nematode Criconemella-Xenoplax. Protoplasma 1992, 171(1-2):1-6.

49. Grundler FMW, Sobczak M, Golinowski W: Formation of wall openings in root cells of Arabidopsis thaliana following infection by the plantparasitic nematode Heterodera schachtii. Eur J Plant Pathol 1998 104(6):545-551.

50. Hofmann J, Youssef-Banora M, de Almeida-Engler J, Grundler FMW: The Role of Callose Deposition Along Plasmodesmata in Nematode Feeding Sites. Mol Plant Microbe In 2010, 23(5):549-557.

51. Hoth S, Stadler R, Sauer N, Hammes UZ: Differential vascularization of nematode-induced feeding sites. P Natl Acad Sci USA 2008, 105(34):12617-12622.

52. Hao PY, Liu CX, Wang YY, Chen RZ, Tang M, Du B, Zhu LL, He G: Herbivoreinduced callose deposition on the sieve plates of rice: An important mechanism for host resistance. Plant Physiol 2008, 146(4):1810-1820.

53. Sijmons PC, Grundler FMW, Vonmende N, Burrows PR, Wyss U: ArabidopsisThaliana as a New Model Host for Plant-Parasitic Nematodes. Plant J 1991, 1(2):245-254

54. Epple P, Apel K, Bohlmann H: An Arabidopsis-Thaliana Thionin Gene Is Inducible Via a Signal-Transduction Pathway Different from That for Pathogenesis-Related Proteins. Plant Physiol 1995, 109(3):813-820.

55. Logemann E, Birkenbihl RP, Ulker B, Somssich IE: An improved method for preparing Agrobacterium cells that simplifies the Arabidopsis transformation protocol. Plant Methods 2006, 2:16.

56. Edwards K, Johnstone C, Thompson C: A simple and rapid method for the preparation of plant genomic DNA for PCR analysis. Nucleic Acids Res 1991, 19(6):1349.

57. Jürgensen K: Untersuchungen zum Assimilat- und Wassertransfer in der Interaktion zwischen Arabidopsis thaliana und Heterodera schachtii. Thesis, Agrar- und Ernährungswissenschaftliche Fakultät. Kiel: Christian-Albrechts University; 2001

58. Livak KJ, Schmittgen TD: Analysis of relative gene expression data using real-time quantitative PCR and the 2(T)(-Delta Delta C) method. Methods 2001, 25(4):402-408.

59. Tornero P, Dangl JL: A high-throughput method for quantifying growth of phytopathogenic bacteria in Arabidopsis thaliana. Plant J 2001 28(4):475-481.

doi:10.1186/1471-2229-13-47

Cite this article as: Ali et al:: Overexpression of the transcription factor RAP2.6 leads to enhanced callose deposition in syncytia and enhanced resistance against the beet cyst nematode Heterodera schachtii in Arabidopsis roots. BMC Plant Biology 2013 13:47.

\section{Submit your next manuscript to BioMed Central and take full advantage of:}

- Convenient online submission

- Thorough peer review

- No space constraints or color figure charges

- Immediate publication on acceptance

- Inclusion in PubMed, CAS, Scopus and Google Scholar

- Research which is freely available for redistribution 